\title{
UNIVERSITÄT
}

LEIPZIG

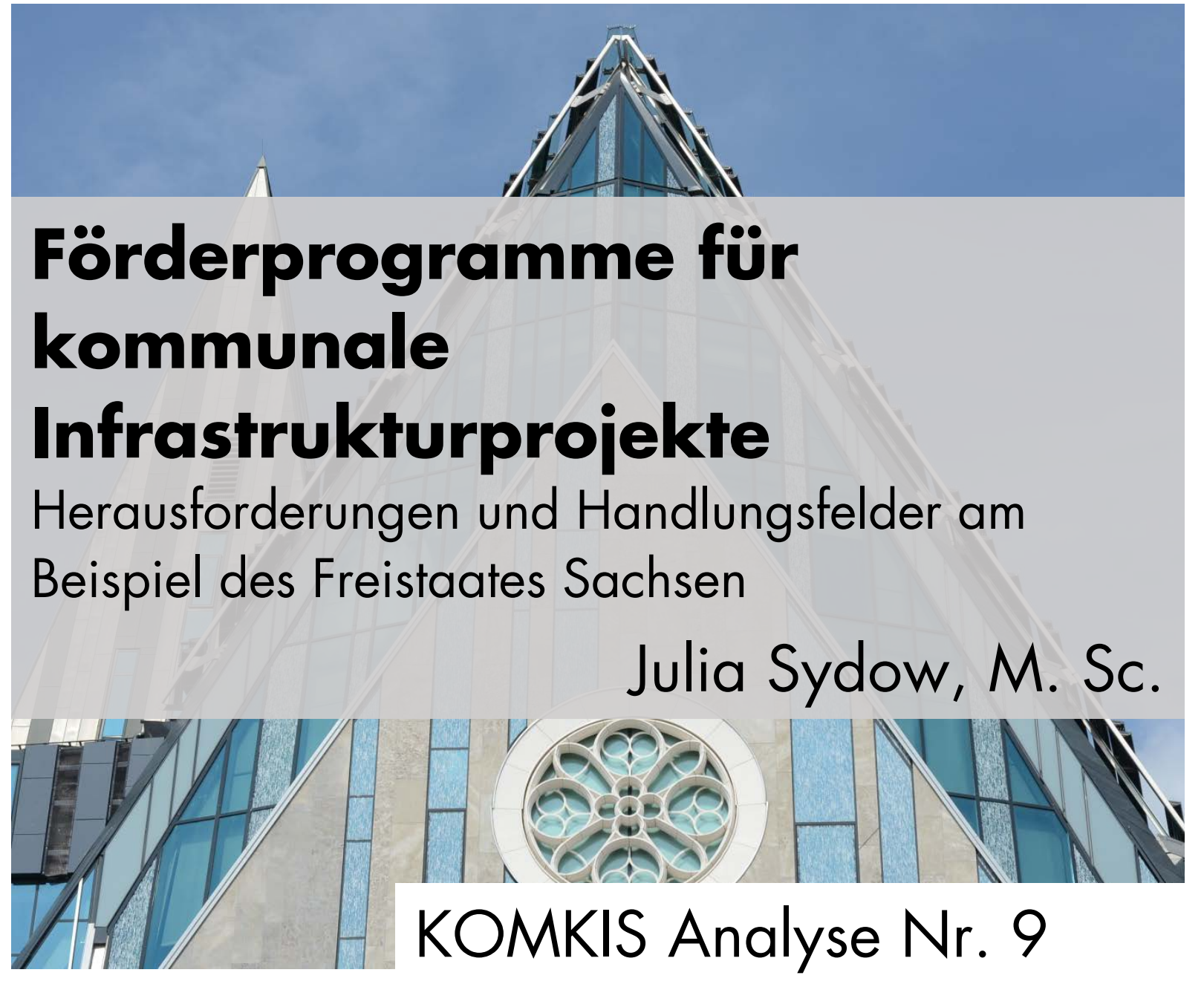


KOMKIS Analyse | Förderprogramme für kommunale Infrastrukturprojekte

Bibliographische Information der Deutschen Nationalbibliothek: Die Deutsche Nationalbibliothek verzeichnet diese Publikation in der Deutschen Nationalbibliographie; detaillierte bibliographische Daten sind im Internet über http:// dnb. d-nb. de abrufbar.

\section{ISSN 2511-7432}

Erscheinungsjahr 2018

Ansprechperson: J ulia Sydow, wissenschaftliche Mitarbeiterin T +49341 9733-626 | F +49341 9733-589 | sydow@wifa.uni-leipzig.de

(c) Kompetenzzentrum für kommunale Infrastruktur Sachsen; alle Rechte vorbehalten. Städtisches Kaufhaus, Universitätsstraße 16, 04109 Leipzig.

Foto: Paul Trainer | Universität Leipzig 


\section{Inhaltsverzeichnis}

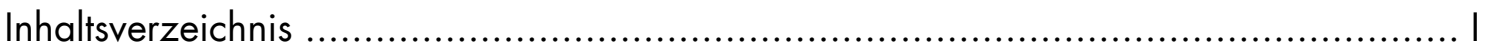

Abbildungs- und Tabellenverzeichnis ..........................................................

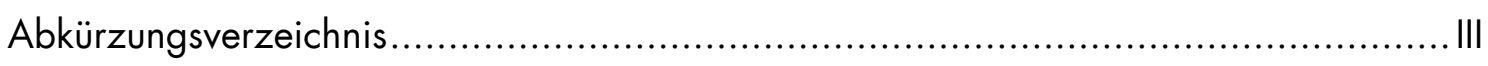

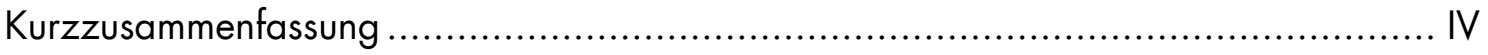

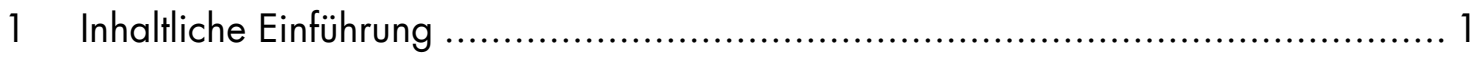

1.1 Fördermittelbegriff - eine rechtliche und finanzwissenschaftliche Einordnung ... 2

1.2 Fördermittellandschaft des Freistaates Sachsen...................................... 5

1.3 Förderprozess - von der Beantragung bis zur Auszahlung ...................... 9

2 Zur Verfügung stehende versus abgerufene Fördermittel ........................... 11

3 Herausforderungen bei der Förderung kommunaler Infrastrukturprojekte............ 16

3.1 Informations- und Zuständigkeitsprobleme ................................... 17

3.2 Ausgestaltung der Förderprogramme ........................................ 20

3.3 Förderprozessumsetzung/-abwicklung ....................................... 26

4 Handlungsfelder für den Freistaat Sachsen......................................... 31

4.1 Einheitliche Datenbank ........................................................... 32

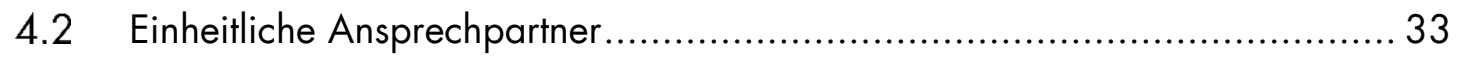

4.3 Standardisierung / Digitalisierung ............................................ 33

4.4 Fachliche Unterstützung der Kommunen ......................................... 34

4.5 Umstrukturierung und Reduzierung der Anzahl an Fördermittelprogrammen .. 35

4.6 Erweiterung der Fördergegenstände .......................................... 36

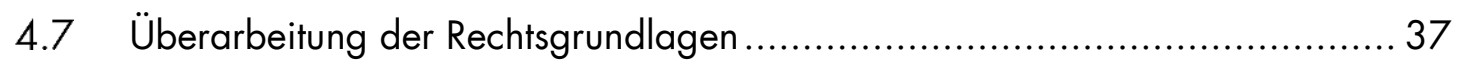

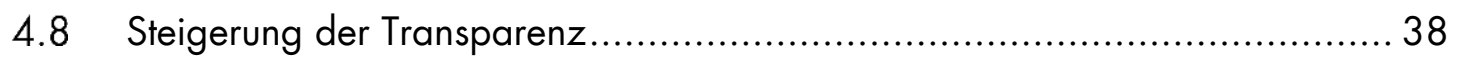

4.9 Verlässlichkeit / Verstetigung der Mittelvergabe.................................. 39

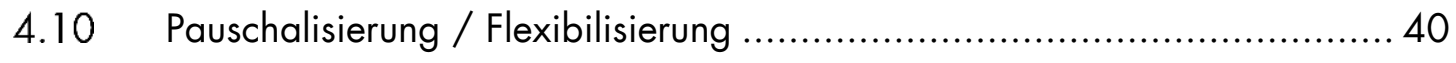

5 Zusammenfassung und Ausblick...................................................... 41

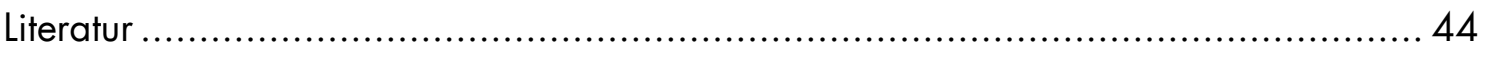

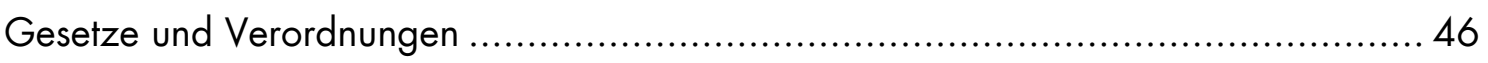




\section{Abbildungs- und Tabellenverzeichnis}

Abbildung 1: Investive Zweckzuweisungen innerhalb des KFA 2015 nach Aufgabenbereichen ....................................................... 14

Abbildung 2: Summe investiver Zuweisungen an Gemeinden außerhalb des KFA

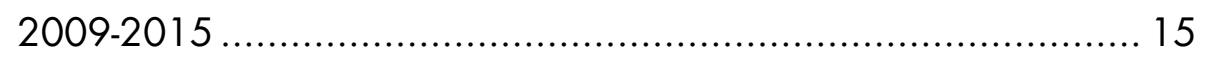

Abbildung 3: Bekanntheitsgrad und Nutzung ausgewählter Förderprogramme ..... 18

Abbildung 4: Befragungsergebnisse zu These 1 ...................................... 19

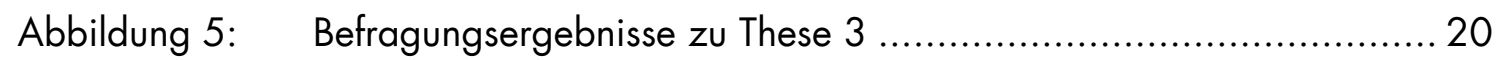

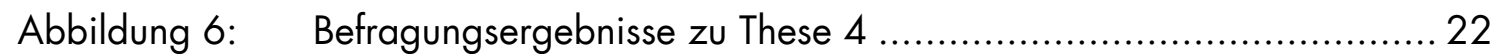

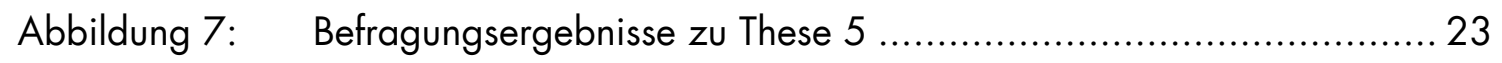

Abbildung 8: Befragungsergebnisse zum Eigenanteil nach Einwohnerklassen ....... 24

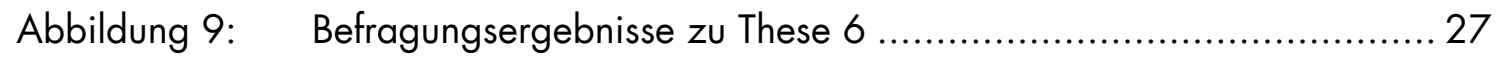

Abbildung 10: Befragungsergebnisse zum Arbeitsaufwand nach Einwohnerklassen 28

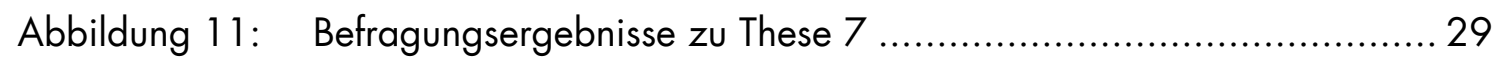

Abbildung 12: Würden Sie eine pauschale Auszahlung der Fördermittel der jetzigen Auszahlungsform vorziehen? ............................................. 30

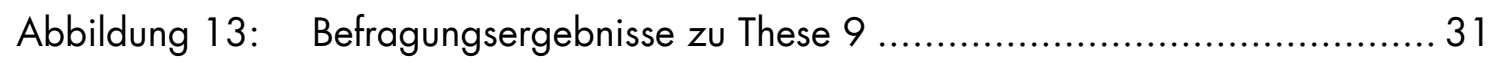




\section{Abkürzungsverzeichnis}

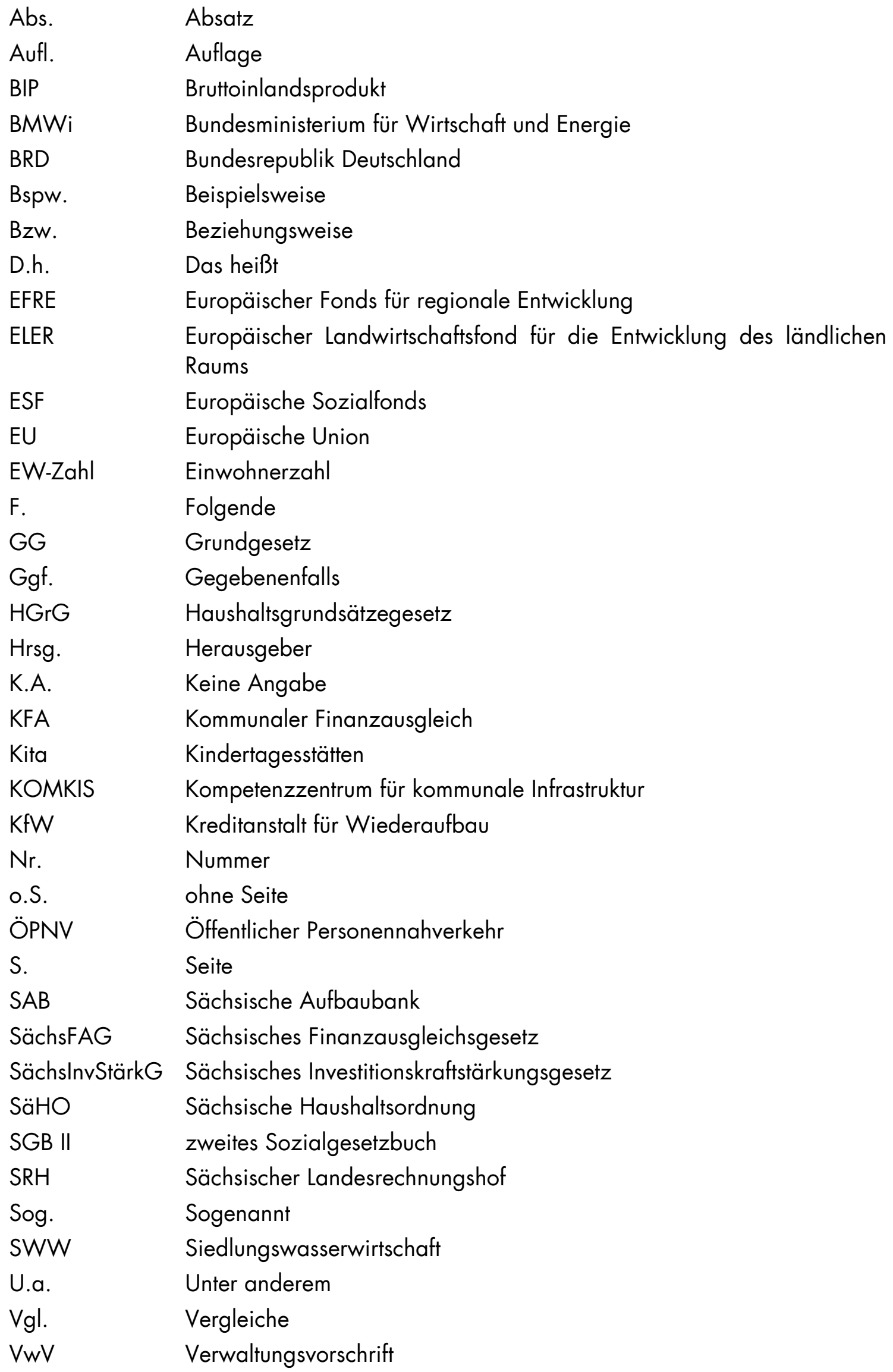




\section{Kurzzusammenfassung}

Die vorliegende KOMKIS Analyse widmet sich der Fördermittelvergabe für kommunale Infrastrukturprojekte am Beispiel des Freistaates Sachsen. Dazu wird der Fördermittelbegriff zunächst aus rechtlicher und finanzwissenschaftlicher Sicht definiert, die Fördermittellandschaft des Freistaates Sachsen grob skizziert sowie ein Überblick über einen beispielhaften Prozess einer Fördermittelvergabe gegeben. Darüber hinaus untersucht die KOMKIS Analyse einerseits gegenwärtig bestehende Herausforderungen im Rahmen der Vergabe von Fördermitteln zur Finanzierung kommunaler Infrastrukturprojekte am Beispiel des Freistaates Sachsen. Andererseits werden auf der Grundlage dieser identifizierten Herausforderungen entsprechende Handlungsfelder zur Vereinfachung eines Förderprozesses und zur Bewältigung bestehender Schwierigkeiten bei der Fördermittelvergabe erarbeitet. Zusammenfassend konnten drei wesentliche Herausforderungen im Rahmen der Fördermittelvergabe identifiziert werden. Diese bestehen einerseits in dem hohen Informationsaufwand und der mangelnden Übersicht über die zahlreichen Zuständigkeiten und andererseits in der generellen Ausgestaltung der Fördermittelprogramme sowie der Umsetzung bzw. dem Vollzug des gesamten Fördervergabeprozesses. Im weiteren Schritt wurden insgesamt zehn Handlungsfelder zur Vereinfachung der Fördermittelvergabe am Beispiel des Freistaates Sachsen erarbeitet und diskutiert. Neben einer einheitlichen Fördermitteldatenbank und einheitlichen Ansprechpartnern zur fachlichen Unterstützung der Kommunen, einer umfangreicheren Digitalisierung und Standardisierung der Fördermittelvergabe sowie der Umstrukturierung bzw. Reduzierung der Anzahl an Fördermittelprogrammen stellen ebenfalls eine Erweiterung der Fördergegenstände über die "klassischen" Investitionen hinaus auf Erhaltungsmaßnahmen relevante Handlungsfelder dar. Darüber hinaus erscheint zur Bewältigung bestehender Herausforderungen im Rahmen der Umsetzung eines Fördermittelvergabeprozesses bspw. die Überarbeitung der Rechtsgrundlagen sinnvoll. Zusätzlich sind ebenfalls die Steigerung von Transparenz durch eine regelmäßige Berichterstattung über die zur Verfügung stehenden Mittel, eine durch die Erweiterung oder Aufstockung von Fördertöpfen realisierte Verstetigung der Mittelvergabe sowie eine Pauschalisierung bzw. Flexibilisierung der Mittelvergabe denkbare Handlungsfelder. 


\section{Inhaltliche Einführung}

Als Reaktion auf den existierenden Investitionsrückstand' stellen Bund und Länder für die kommunale Ebene verstärkt Fördermittel zur Bewältigung dieses Rückstandes zur Verfügung. Diese Fördermittel werden auch dringend benötigt. Viele sächsische Kommunen können Infrastrukturprojekte nur mithilfe dieser Unterstützung realisieren, so ein Ergebnis der Befragung des Kompetenzzentrums für kommunale Infrastruktur Sachsen (KOMKIS) im Jahr 2016 . $^{2}$ Andererseits haben die Kommunen bundesweit zunehmend Schwierigkeiten, die bereitgestellten Mittel fristgerecht abzurufen. In den Medien häufen sich Meldungen, wie "Kommunen investieren zu langsam"3 oder "Wo die Bundesmittel nicht verbaut wer$\operatorname{den}^{\prime 4}{ }^{5}$

Die vorliegende KOMKIS Analyse thematisiert vor dem Hintergrund Herausforderungen im Zusammenhang mit der Förderung kommunaler Infrastrukturprojekte. Zuvor gilt es, zu klären, in welchem Umfang bereitgestellte Fördermittel tatsächlich ungenutzł bleiben. Anknüpfend an die Analyse der Ursachen für einen unzureichenden Fördermittelabruf werden schließlich potenzielle Handlungsfelder benannt, um auf einen effizienteren Mittelabfluss hinzuwirken. Die Analyse wird am Beispiel des Freistaates Sachsen vorgenommen. Viele Herausforderungen dürften dennoch in anderen Bundesländern in vergleichbarer Form auftreten, die skizzierten Lösungsansätze sind somit grundsätzlich übertragbar.

Das erste Kapitel dient zunächst der allgemeinen Klärung des Fördermittelbegriffs: Welche rechtlichen Vorschriften liegen der Förderung zugrunde? Wie sind öffentliche Fördermittel ökonomisch einzuordnen? Welche Rolle spielt diese kommunale Einnahmekategorie aus finanzwissenschaftlicher Sicht? Des Weiteren werden die Fördermittellandschaft des Freistaates Sachsen sowie ein typischer Förderprozess skizziert. Über die in Kapitel 2 anknüpfende Erläuterung der Diskrepanz zwischen den zur Verfügung stehenden und den tatsächlich abgerufenen Fördermitteln hinaus werden in Kapitel 3 die drei wesentlichen Herausforderungen im Rahmen der Fördermittelvergabepraxis bei kommunalen Infrastrukturprojekten charakterisiert. Anschließend werden in Kapitel 4 insgesamt zehn, auf der

\footnotetext{
Vgl. bspw. Scheller/Schneider (2017).

Vgl. Kilian/Hesse/Redlich (2016).

Vgl. Drebes/Quadbeck (2016).

Vgl. Deutscher Städte- und Gemeindebund 2017.

Vgl. bspw. Frankfurter Allgemeine Sonntagszeitung (2017); Rossbach (2016).
} 
Grundlage dieser Ergebnisse erarbeiteten Handlungsfelder zur Vereinfachung der Fördermittelvergabe am Beispiel des Freistaates Sachsen diskutiert. Das Kapitel 5 gibt einen kurzen Überblick über die wesentlichen Ergebnisse der Analyse sowie einen Ausblick.

\subsection{Fördermittelbegriff - eine rechtliche und finanzwissen- schaftliche Einordnung}

Fördermittel sind finanzielle Zuwendungen der öffentlichen Hand (EU, Bund oder Länder), die in der Regel der Erreichung bestimmter politischer oder wirtschaftlicher Ziele dienen ${ }^{6}$. Es handelt sich folglich nicht um finanzielle "Geschenke", sondern der Fördermittelempfänger - unabhängig davon, ob privater oder öffentlicher Akteur - hat bestimmte Kriterien zu erfüllen.

Rechtlich sind Fördermittel dem Oberbegriff Zuwendungen zuzuordnen. Der Zuwendungsbegriff ist seit der Haushaltsrechtsreform von 1969 in § 14 Haushaltsgrundsätzegesetz ( $\mathrm{HGrG}$ ) sowie in $\S 23$ der Haushaltsordnungen des Bundes und der Länder verankert. Zuwendungen bezeichnen demnach „Ausgaben und Verpflichtungsermächtigungen für Leistungen an Stellen außerhalb der Verwaltung des Bundes oder des Landes zur Erfüllung bestimmter Zwecke" ${ }^{\prime 7}$. Je nach Mittelempfänger wird begrifflich differenziert: Zuwendungen an Gebietskörperschaften, bspw. Kommunen werden Zuweisungen genannt, Mittelflüsse an den Privatsektor gelten als Zuschüsse. Zuwendungen im Allgemeinen dürfen allerdings nur veranschlagt werden, „wenn der Staat an der Erfüllung durch solche Stellen ein erhebliches Interesse hat, das ohne die Zuwendungen nicht oder nicht im notwendigen Umfang befriedigt werden kann" ${ }^{\prime 8}$. Das bedeutet zum einen, dass die Erbringung dieser Leistungen im Ermessen der zuteilenden Verwaltung liegt, d. h., die Zuwendungsempfänger haben keinen gesetzlichen Anspruch auf die Leistung. ${ }^{9}$ Zum anderen zeigt sich in dieser Formulierung, dass die übergeordnete Rechtsgrundlage für die Förderung kommunaler Infrastrukturprojekte eher auf einen Ausnahmetatbestand abstellt und weniger auf einen Regelfall rekurriert. ${ }^{10}$

\footnotetext{
Vgl. Sächsischer Rechnungshof (2016), S. 107.

$\S 14 \mathrm{HGrG}$.

$\S 23 \mathrm{SäHO}$.

Vgl. Aulbert (2010), S. 26-28.

10 Dies wird bei der Analyse der Herausforderungen und auch der potenziellen Handlungsfelder zu berücksichtigen sein.
} 
Zu den weiteren Auflagen im Zuge der Gewährung von Zuwendungen zählt der Nachweis der zweckentsprechenden Verwendung der Zuweisungen bzw. Zuschüsse. ${ }^{11}$ Hierfür sind die zu prüfende Dienststelle sowie Art und Weise des Verwendungsnachweises festzulegen. Aus dem Grundsatz der Wirtschaftlichkeit (§ 7 Sächsische Haushaltsordnung (SäHO)), der auch für die Bewilligung von Zuwendungen gilt, ${ }^{12}$ wird zudem indirekt die Notwendigkeit der Erfolgskontrolle abgeleitet, d.h. Förderprogramme sollten nach Abschluss hinsichtlich ihrer Zielerreichung, Wirksamkeit und Effizienz evaluiert werden. ${ }^{13}$ Dies hat wiederum Auswirkungen auf die Anforderungen im vorgelagerten Förderprozess und entsprechende Förderrichtlinien, von der Antragstellung über die Bewilligung bis hin zur Dokumentation der Mittelverwendung. ${ }^{14}$

Näheres zu Zuwendungsarten oder zur (standardisierten) Gliederung der Förderrichtlinien regeln die Verwaltungsvorschriften zur SäHO. So werden bei der Art der Zuwendung verlorene Zuschüsse (Finanzhilfen, Prämien), Schuldendiensthilfen (Zinszuschüsse) und andere nicht rückzahlbare Leistungen sowie zweckgebundene Darlehen und andere bedingt oder unbedingt rückzahlbare Leistungen unterschieden. ${ }^{15}$ Förderrichtlinien werden für einen bestimmten Zuwendungszweck erlassen und definieren die sachlichen Voraussetzungen der Förderung. Sie enthalten u.a. Angaben zum Zuwendungszweck, Gegenstand der Förderung, Zuwendungsempfänger sowie Art und Umfang der Zuwendungen. ${ }^{16}$

Aus finanzwissenschaftlicher Sicht stellen Fördermittel bzw. Zuweisungen Transfers innerhalb des öffentlichen Sektors dar. ${ }^{17}$ Außerdem handelt es sich um eine kommunale Einnahmeart, die für die Finanzausstattung der Kommunen von großer Relevanz ist. Zuweisungen sind dabei durch einen deutlich geringeren Autonomiegehalt gekennzeichnet als andere kommunale Einnahmearten wie bspw. Gemeindestevern oder Entgeltabgaben, d. h., die Kommunen haben in der Regel keinen Einfluss auf Höhe und Struktur der Zuweisungen. Sie werden ihnen von übergeordneten staatlichen Ebenen zugeteilt. ${ }^{18}$

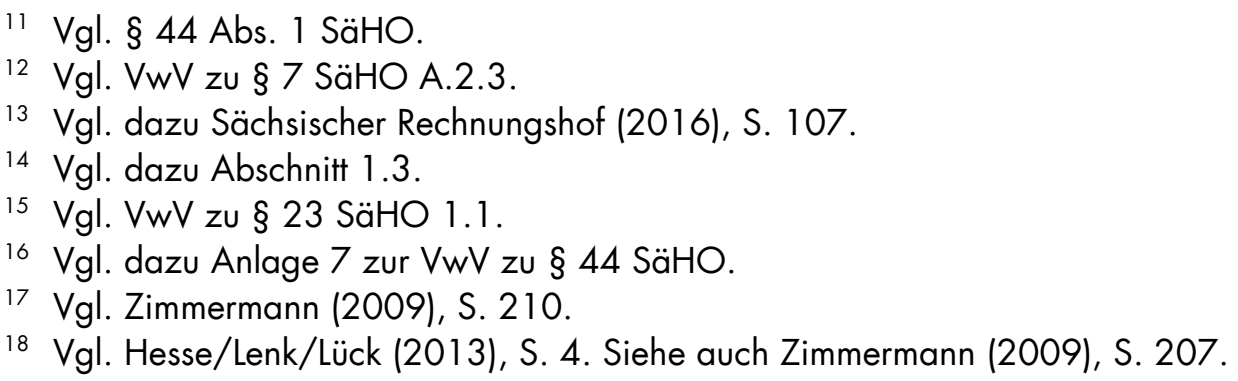


Bei den einzelnen Zuweisungsarten variiert wiederum deutlich der Grad der Zweckbindung. ZIMMERMANN unterscheidet Erstattungen für Auftragsangelegenheiten, Zuweisungen mit Zweckbindung und Miffinanzierung durch die Gemeinde, Zuweisungen nur mit Zweckbindung sowie Zuweisungen ohne Auflage. ${ }^{19}$ Kostenerstattungen sind dabei sichtbarer Ausdruck des Konnexitätsprinzips. Das bedeutet, dass bspw. die kommunale Ebene eine Aufgabe des Bundes oder des Landes übernommen hat und die damit verbundenen Kosten erstattet bekommt. Zuweisungen ohne Auflage in Form von Schlüssel- oder Bedarfszuweisungen weisen dagegen keine (Schlüsselzuweisungen) bzw. nur eine geringere (Bedarfszuweisungen) Zweckbindung auf. Die im Fokus dieser Analyse stehenden antragsgebundenen Fachförderprogramme sind überwiegend der Kategorie Zuweisungen mit Zweckbindung und Miffinanzierung durch die Gemeinde zuzuordnen. In Ausnahmefällen gilt nur die Zweckbindung, d. h. die Finanzierung wird zu 100 Prozent von der übergeordneten Stelle übernommen.

Zweckgebundene Zuweisungen ermöglichen es, der übergeordneten Gebietskörperschaft die Verwendung der von ihr bereitgestellten Finanzmittel aktiv zu stevern und dadurch indirekt Einfluss auf die kommunale Aufgabenwahrnehmung zu nehmen (sog. „goldener Zügel“"). Durch die Bereitstellung von Fördermitteln für ausgewählte Aufgabenbereiche wirkt die "gebende" Ebene auf eine kommunale Aufgabenerfüllung gemäß ihrer Präferenzen hin $^{20}$, da für die Kommunen Anreize entstehen, insbesondere in den geförderten Bereichen zu investieren und Projekte umzusetzen. In dem Zusammenhang wird auch von einer "Meritorisierung" der Gemeindeaufgaben gesprochen: Die höhere Ebene unterstützł dabei kommunale Aufgaben, an deren Erfüllung sie "ein erhebliches Interesse" ${ }^{21}$ hat, die von der Gemeinde jedoch nicht oder nicht in der gewünschten Form erfüllt werden. Mittels der zweckgebundenen Zuweisungen versucht die übergeordnete Gebietskörperschaft die aus ihrer Sicht verzerrten Präferenzen der Gemeindebürger zu korrigieren. ${ }^{22}$ Zugleich soll der finanzielle Eigenanteil der Kommunen Mitnahmeeffekte vermeiden.

Vgl. Zimmermann (2009), S. 112-115.

20 Vgl. Zimmermann (2009), S. 214.

$21 \S 23 \mathrm{SäHO}$.

22 Zur "Meritorisierung" von Gemeindeaufgaben siehe Zimmermann (2009), S. 214. 
Die Steuerung kommunalen Handelns durch zweckgebundene Landeszuweisungen ist jedoch aus finanzwissenschaftlicher Perspektive auch kritisch zu sehen. So stehen die Zweckbindung und die damit verbundene Einschränkung der Einnahmenautonomie einer kraftvollen kommunalen Selbstverwaltung entgegen, die sich durch die Möglichkeit eigenverantwortlicher dezentraler Entscheidungen auszeichnet. ${ }^{23}$ Weiterhin ist nicht auszuschließen, dass aus der Zweckbindung Fehlallokationen öffentlicher Mittel resultieren, wenn Kommunen bestimmte Investitionsvorhaben forcieren, nur um eine Ko-Finanzierung aus Fördermitteln zu nutzen und dafür andere Vorhaben vernachlässigen, die für die Kommune jedoch eine höhere Priorität gehabt hätten. ${ }^{24}$ Durch die Mitfinanzierung entsteht zudem eine doppelte Ablenkung der gemeindlichen Prioritäten, da ggf. Mittel aus anderen Verwendungen abgezogen werden müssen. ${ }^{25}$ Dieser Zusammenhang ist in den ostdeutschen Kommunen von besonderer Relevanz, da diese typischerweise eine deutlich höhere Zuweisungsabhängigkeit aufweisen als westdeutsche Kommunen. ${ }^{26}$

\subsection{Fördermittellandschaft des Freistaates Sachsen}

Das Förderprofil des Freistaates Sachsen, das regelmäßig ergänzend zum Sächsischen Staatshaushaltsplan veröffentlicht wird, vermittelt einen Eindruck der vielschichtigen sächsischen Fördermittellandschaft. Für das Haushaltsjahr 2017 ist danach ein Fördervolumen in Höhe von insgesamt 2,68 Milliarden Euro vorgesehen. Förderschwerpunkte sind wie in den Vorjahren die Bereiche Bildung (knapp $40 \%$ ) und Wirtschaftsförderung (13\%). Knapp 45 Prozent des gesamten Fördervolumens dienen dabei der Förderung investiver Maßnahmen, die übrigen Mittel entfallen auf konsumtive Ausgaben. Zusätzlich zu den Kommunen zählen Unternehmen, Vereine, Zweckverbände, aber auch Privatpersonen zu den möglichen Zuwendungsempfängern.

Neben dem Freistaat Sachsen stellen die Europäische Union (EU) und der Bund Mittel zur Förderung bereit. Diese werden in der Regel zunächst im Landeshaushalt vereinnahmt und können daraufhin von den Förderbegünstigten über die zuständigen Landesstellen beantragt werden. Vom aktuellen Fördervolumen für 2017 stellt der Freistaat Sachsen mit rund

\footnotetext{
23 Vgl. Hesse/Lenk/Lück (2013), S. 5.

24 Vgl. Hesse/Lenk/Lück (2013), S. 5.

25 Vgl. Zimmermann (2009), S. 113.

26 Vgl. dazu Lenk/Hesse/Kratzmann (2017), S. 60.
} 
70 Prozent gut zwei Drittel der Mittel selbst bereit. Ergänzend werden rund 16 bzw. 13 Prozent aus EU- bzw. Bundesmitteln refinanziert. ${ }^{27}$

Förderrichtlinien, die auf Ebene des Freistaates erstellt werden, determinieren den Rahmen, nach dem die im Landeshaushalt vereinnahmten Mittel von EU, Bund und Land zugeteilt werden. Dabei können einerseits spezielle Richtlinien für neu aufgelegte Förderprogramme erstellt werden. ${ }^{28}$ Andererseits werden zusätzliche Mittel häufig nach bereits bestehenden Richtlinien zugeteilt. Im aktuellen Förderprofil des Freistaates Sachsen sind alle Förderrichtlinien und die zugeordneten Haushaltsstellen aufgeführt, wobei einer Förderrichtlinie meist mehrere Haushaltsstellen zugeordnet sind. Im Haushaltsplan finden sich wiederum unter den Haushaltsstellen die entsprechenden Rechtsgrundlagen (Förderrichtlinien), nach denen die Mittel beantragt und zugeteilt werden können, sodass die Verknüpfungen wechselseitig nachvollziehbar sind.

Für die vorliegende Analyse ist nur ein Teil dieser Fördermittellandschaft relevant. Zum einen sind nur Kommunen als Zuwendungsempfänger Gegenstand der Analyse, zum anderen werden in erster Linie Förderbereiche betrachtet, die der kommunalen Infrastruktur zuzuordnen sind. Informationen darüber, welchen Anteil diese Zuweisungen am gesamten Fördervolumen einnehmen, sind jedoch nicht ohne weiteres aus dem Förderprofil ableitbar. ${ }^{29}$ Eine ungefähre Größenordnung kann der jährlichen Haushaltsrechnung ${ }^{30}$ entnommen werden. Danach waren im Haushalt 2015 Zuweisungen für Investitionen an Gemeinden und Gemeindeverbände in Höhe von knapp 520 Millionen Euro (ohne Zuweisungen im Rahmen des kommunalen Finanzausgleichs) vorgesehen. ${ }^{31}$ Aus der allgemeinen Finanzausgleichsmasse des kommunalen Finanzausgleichs wurden zusätzlich 110 Millionen Euro für investive Zweckzuweisungen bereitgestellt. ${ }^{32}$ Damit stand knapp ein Viertel des gesamten Fördervolumens im Freistaat Sachsen zur Förderung investiver Zwecke der Kommunen

27 Vgl. Freistaat Sachsen (2018), S. 6.

28 Dies ist bei EU-Programmen häufiger der Fall, da spezielle EU-Vorgaben bei der Förderung zu berücksichtigen sind.

29 Hierzu müsste händisch untersucht werden, nach welchen Richtlinien die Kommunen zu den Begünstigten zählen und in welcher Höhe Mittel an den entsprechenden Haushaltsstellen vorgesehen sind.

30 Anlage zur Nachweisung der Ausgaben an den kommunalen Bereich.

31 Vgl. Haushaltsrechnung des Bundes 2015, Einzelplan 15, Anlage A/2, S. 125. Hinzu kommen nicht abgerufene Mittel aus dem Vorjahr. Vgl. dazu Kapitel O. Das gesamte Fördervolumen belief sich 2015 auf 2,68 Milliarden Euro. Vgl. Freistaat Sachsen (2016).

32 Vgl. § 24 Abs. 1 Finanzausgleichsgesetz in der Fassung vom 01.01.2015. 
zur Verfügung. Auf die Abweichung zwischen bereitgestellten und abgerufenen Fördermitteln wird im nachfolgenden Kapitel eingegangen.

Zuvor wird im nachfolgenden Abschnitt ein typischer Förderprozess von der Beantragung bis zur Auszahlung skizziert, um zu verdeutlichen, an welchen Stellen potenziell Schwierigkeiten beim Fördermittelabruf auftreten können. Je nach Geldgeber können die Anforderungen im Förderprozess unterschiedlich ausgestaltet sein. Vor dem Hintergrund wird im Folgenden nochmals genauer auf die jeweiligen Zielsetzungen und Rechtsgrundlagen der drei Geldgeber eingegangen.

Der Freistaat Sachsen hat nach Artikel 87 der Sächsischen Verfassung die Pflicht, die kommunalen Träger der Selbstverwaltung finanziell angemessen auszustatten, sodass diese ihre Aufgaben erfüllen können. Zuweisungen sind eine Möglichkeit den Kommunen Mittel zur Aufgabenerfüllung zur Verfügung zu stellen. Je nach Zielsetzung, Fördergegenstand und Verteilung der Bedarfe sind pauschale oder zweckgebundene Zuweisungen zielführender. Der rechtliche Rahmen zur Ausgestaltung der Zuweisungen wird, wie im vorigen Abschnitt erläutert, durch die $\S \S 23,44$ der SäHO bestimmt und durch die entsprechenden Verwaltungsvorschriften zur Erstellung der Förderrichtlinien ergänzt. Die Kommunen weisen daraufhin nach, dass sie die vom Land erhaltenen Mittel ordnungsgemäß verwendet haben. Diese Vorgaben zur Verwendung der Landesmittel kann der Gesetzgeber des Freistaates (im Rahmen des geltenden Rechts) selbst beeinflussen.

Bei übergeordneten Geldgebern wie dem Bund und der EU kommt dagegen eine weitere Ebene hinzu. Für den Bund ist bei der Gewährung von Zuwendungen einerseits die Bundeshaushaltsordnung maßgeblich und damit eine ähnliche Rechtsgrundlage wie für den Freistaat Sachsen. Andererseits gilt für den Bund einschränkend der Artikel 104 b des Grundgesetzes, nach dem der Bund Finanzhilfen für besonders bedeutsame Investitionen der Länder und Gemeinden gewähren darf, sofern diese im Rahmen der Gesetzgebungsbefugnisse des Bundes liegen. Die Fördermöglichkeiten des Bundes sind somit auf investive Maßnahmen und auf Bereiche, in denen die Gesetzgebungskompetenz des Bundes gilt, begrenzt. Diese Einschränkung schlägt sich bspw. in der Zweiteilung des sächsischen Förderprogramms "Brücken in die Zukunft" nieder, bei dem das "Budget Bund" gegenüber dem „Budget Sachsen” deutlich eingeschränkte Fördermöglichkeiten bietet. Weiterhin darf der Bund laut Art. 104b GG nur den Ländern unmittelbar Finanzhilfen gewähren. Direkte Finanzhilfen vom Bund an die Kommunen sind laut Grundgesetz nicht erlaubt, da die 
Kommunen verfassungsrechtlich den Ländern zugeordnet sind. ${ }^{33}$ Wenn die Länder die Bundesmittel wiederum an die Kommunen weiterreichen, müssen die Kommunen die gemäß Bundesvorgaben korrekte Verwendung der Mittel gegenüber dem Land nachweisen, während das Land gegenüber dem Bund berichtspflichtig ist.

Eine ähnliche Kaskade entsteht bei der Verwendung von EU-Mitteln. Die EU zielt mit ihrer Kohäsions- und Strukturpolitik auf eine Festigung des wirtschaftlichen, sozialen und territorialen Zusammenhalts in der Union und fördert vor dem Hintergrund insbesondere in strukturschwachen Regionen Maßnahmen zur Steigerung von Wachstum und Beschäftigung. Hierfür stehen bspw. die Europäischen Struktur- und Investitionsfonds zur Verfügung, zu denen u.a. der Europäische Fonds für regionale Entwicklung (EFRE), der Europäische Sozialfonds (ESF) und der Europäischen Landwirtschaftsfonds für die Entwicklung des ländlichen Raums (ELER) zählen. Der überwiegende Teil dieser Mittel wird von den EU-Staaten selbst verwaltet (in Deutschland meist von den Bundesländern), dennoch ist gegenüber der EU die ordnungsgemäße Verwendung zu dokumentieren. Auf Ebene der Mitgliedsstaaten wird zunächst eine Partnerschaftsvereinbarung erstellt und mit der Europäischen Kommission verhandelt, die sich mit der Gesamtstrategie des Mitgliedsstaates befasst. Die genaue Verwendung der Mittel regeln schließlich die Bundesländer im Rahmen von sog. Operationellen Programmen, die jedoch wiederum von der Europäischen Kommission zu genehmigen sind und mit dem nationalen strategischen Rahmen vereinbar sein müssen.

Aus den Europäischen Struktur- und Investitionsfonds erhält Deutschland im Förderzeitraum 2014-2020 insgesamt 19,2 Milliarden Euro, davon entfallen rund 3,6 Milliarden Euro auf den Freistaat Sachsen. Im Hinblick auf die kommunale Infrastruktur sind insbesondere die EFRE-Mittel von Bedeutung. Für den gesamten Förderzeitraum stehen dem Freistaat Sachsen hier 2,09 Milliarden Euro bzw. jährlich knapp 300 Millionen Euro zur Verfügung. ${ }^{34}$ Für die Verteilung der Mittel innerhalb Sachsens und die jeweilige Förderintensität ist darüber hinaus die Einstufung der Region ausschlaggebend. ${ }^{35}$ Während die Regionen Dres-

33 Im Zuge der Neuordnung der Bund-Länder-Finanzbeziehungen ab 2020 wird dieses Kooperationsverbot etwas gelockert.

${ }^{34} \mathrm{Vgl}$. Europäische Kommission (2018)

35 Weniger entwickelte Regionen: BIP pro Kopf < 75 \% des EU-Durchschnitts; Übergangsregionen: BIP pro Kopf 75 bis $90 \%$ des EU-Durchschnitts; Stärker entwickelte Regionen: BIP pro Kopf > $90 \%$ des EU-Durchschnitts. 
den und Chemnitz im Förderzeitraum 2014-2020 noch zu den Übergangsregionen zählen, hat die Region Leipzig im maßgeblichen Bezugszeitraum 2007 bis 2009 mit einem BIP pro Kopf in Höhe von 90,02 Prozent des EU-Durchschnitts die Schwelle für eine Einstufung als stärker entwickelte Region knapp überschritten und erhält damit eine geringere Förderintensität. ${ }^{36}$ Für die nächste Förderperiode (2021-2027) ist nach bisheriger Systematik eine höhere Einstufung der Region Dresden wahrscheinlich, während der Region Chemnitz mit einem BIP je Einwohner von aktuell knapp unter 90 Prozent des EU-Durchschnitts eine knappe Entscheidung bevorsteht. Hierbei sind allerdings die Auswirkungen des Brexits noch nicht berücksichtigt. Wenn man Großbritannien aus dem aktuellen EUDurchschnitt des BIP je Einwohner herausrechnet, liegen alle sächsischen Regionen eindeutig bei über 90 Prozent des EU-Durchschnitts und würden damit nach bisheriger Systematik zu den stärker entwickelten Regionen der Europäischen Union zählen. Der tatsächliche Brexit würde die sächsische Fördermittellandschaft demnach spürbar verändern.

\subsection{Förderprozess - von der Beantragung bis zur Auszahlung}

Am Beginn des Förderprozesses stehen ein geplantes kommunales Infrastrukturprojekt oder alternativ die Initiative bzw. Ausschreibung eines Fördermittelgebers. Im Zuge des Programms "Brücken in die Zukunft” waren kreisfreie Städte, Landkreise und Gemeinden bspw. dazu angehalten, zunächst Maßnahmenpläne für das jeweils zur Verfügung stehende Budget zu erarbeiten, ehe die Fördermittel für die einzelnen Projekte beantragt werden konnten. Im ersten Fall wird die Verfügbarkeit von Fördermitteln für ein unabhängig von aktuellen Förderinitiativen geplantes Projekt geprüft.

Dabei sind zunächst potenzielle Förderrichtlinien im Hinblick auf ihre Zuwendungsvoraussetzungen zu prüfen. Wenn das Programm voraussichtlich geeignet ist, kann die Kommune einen Förderantrag stellen. Je nach Programm und Richtlinie sind dabei bestimmte Fristen einzuhalten. In der Regel ist bei allen Antragsverfahren - unabhängig vom Förderbereich - ein Antrag auf Gewährung einer Zuwendung ${ }^{37}$ zu stellen. Dieser allgemeine Teil der

36 Vgl. Staatsministerium für Wirtschaft, Arbeit und Verkehr des Freistaates Sachsen (2014), S. 13,19. In stärker entwickelten Regionen können maximal 50 \% der zuschussfähigen Ausgaben durch EFRE-Mittel finanziert werden. In Übergangsregionen liegt die Obergrenze bei $60 \%$, in weniger entwickelten Regionen bei $85 \%$.

$37 \mathrm{Vgl}$. Muster la zu § 44 SäHO. Die Sächsische Aufbaubank verwendet ein eigenes Formular, das aber inhaltlich ähnlich aufgebaut ist. 
Antragsunterlagen enthält eine detaillierte Maßnahmenbeschreibung, damit die entsprechende Bewilligungsstelle prüfen kann, welche Kosten zuwendungsfähig sind. Weiterhin ist ein Finanzierungsplan zum Vorhaben vorzulegen, der Auskunft darüber gibt, welcher Kostenanteil durch Zuwendungen, Eigenmittel oder aus sonstigen Finanzierungsquellen gedeckt werden soll.

Neben diesem allgemeinen Formular sind je nach Bewilligungsstelle und Fördergegenstand weitere Unterlagen einzureichen, wobei träger- und maßnahmenbezogene Unterlagen unterschieden werden. Zu den trägerbezogenen Unterlagen zählen bspw. Angaben zu den finanziellen Verhältnissen des potenziellen Zuwendungsempfängers, die durch eine sog. Gemeindewirtschaftliche Stellungnahme der zuständigen Rechtsaufsichtsbehörde komplettiert werden. ${ }^{38}$ Letztere bescheinigt dem Antragsteller die Sicherstellung der Gesamtfinanzierung des Vorhabens. Maßnahmenbezogene Unterlagen sind dagegen je nach Art der Maßnahme eine Zustandsanalyse des zu sanierenden Objekts oder eine Sachverständigenerklärung bspw. bei energetischen Maßnahmen. Des Weiteren können Angaben zur Abgrenzung zu anderen Förderungen oder ein Grundbuchauszug erforderlich sein.

Wenn die Unterlagen bei der Antrags- bzw. Bewilligungsstelle eingegangen sind, prüff diese, ob die Zuwendungsvoraussetzungen erfüllt sind. Ein Anspruch auf die Gewährung von Zuwendungen - auch bei Erfüllung aller Zuwendungsvoraussetzungen - besteht jedoch nicht, sondern die Bewilligungsstelle entscheidet im Rahmen der verfügbaren Haushaltsmittel. ${ }^{39} \mathrm{Im}$ Falle der Bewilligung erhält die Kommune als Zuwendungsempfänger einen Bewilligungs- bzw. Zuwendungsbescheid, der Auskunft gibt über Art und Höhe der Förderung, den Bewilligungszeitraum und über ggf. geltende besondere Nebenbestimmungen. ${ }^{40}$ Erst nach Bekanntgabe des Zuwendungsbescheides darf mit dem Vorhaben begonnen werden. ${ }^{41}$ Eine Förderung bereits begonnener Vorhaben ist in der Regel nicht möglich. Ein vorzeitiger Beginn der Maßnahmen kann jedoch in Ausnahmefällen genehmigt werden.

38 Vgl. Muster 2 zu VwV zu § 44 SäHO.

39 Vgl. Anlage 7 zu $\bigvee w V$ zu § 44 SäHO.

40 Vgl. Muster lc zu VwV zu § 44 SäHO.

${ }^{41}$ Als Vorhabensbeginn gilt grundsätzlich der Abschluss eines der Ausführung zuzurechnenden Lieferungs- und Leistungsvertrages. Vgl. $V_{w} V$ zu $§ 44$ SäHO, A.1.3.1. 
Bezüglich der Auszahlung der Fördermittel gibt die VwV zu § 44 SäHO nur einen Rahmen vor. Einerseits dürfen Zuwendungen nicht eher ausgezahlt werden, als sie voraussichtlich innerhalb von zwei Monaten nach Auszahlung für fällige Zahlungen im Rahmen des Zuwendungszwecks benötigt werden. Zu diesem Zweck können die Zuwendungsempfänger einen Antrag auf Auszahlung ${ }^{42}$ stellen. Andererseits kann die Bewilligungsbehörde die Auszahlung der gesamten Zuwendung von der Vorlage des Verwendungsnachweises abhängig machen. ${ }^{43}$ In diesen Fällen ist bis zur endgültigen Prüfung der Verwendungsnachweise eine Vorfinanzierung der Maßnahmen seitens der Kommunen erforderlich. Unabhängig vom Zeitpunkt der Auszahlung sind die Zuwendungsempfänger jedoch verpflichtet die Verwendung der Mittel bis zum Abschluss des Verfahrens gegenüber dem Geldgeber in Form von Verwendungsnachweisen ${ }^{44}$ zu dokumentieren.

\section{Zur Verfügung stehende versus abgerufene Fördermittel}

„Kommunen rufen bereitgestellte Fördermittel nicht oder nur unzureichend ab." Diese eingangs auf Basis aktueller Schlagzeilen ${ }^{45}$ aufgestellte These gilt es im Folgenden zu prüfen und in ihrer Größenordnung zu konkretisieren. Dies ist angesichts der komplexen Fördermittellandschaft, in der Mittel von unterschiedlichen Geldgebern in ein Programm fließen oder eine Förderrichtlinie für mehrere Haushaltstitel maßgeblich ist ${ }^{46}$, keine triviale Frage. Eine naheliegende Methode wäre die Ermittlung einer jährlichen Abrufquote, im Rahmen derer die von Kommunen im jeweiligen Jahr abgerufenen Fördermittel dem gesamten für Kommunen zur Verfügung stehenden Fördervolumen gegenübergestellt werden. Dabei ergeben sich jedoch zahlreiche Schwierigkeiten:

In erster Linie stellt die Beschaffung der nötigen Informationen über die tatsächlich abgerufenen Fördermittel eine Herausforderung dar. Das Förderprofil des Freistaates Sachsen

\footnotetext{
42 Vgl. Muster 3 zu VwV zu § 44 SäHO.

43 Vgl. VwV zu § 44 SäHO, A.7.1 bzw. A.5.5.6.

44 Vgl. Muster 4 zu § 44 SäHO.

45 Vgl. Kapitel 0.

46 Vgl. Abschnitt 1.2.
} 
gibt zwar Auskunft über das jährlich bereitgestellte Fördervolumen, allerdings nicht differenziert nach Zuwendungsempfängern, wie bereits in Abschnitt 1.2 erläutert. Auch die Daten der amtlichen Statistik sind diesbezüglich nicht zielführend. Auskünfte über die tatsächlich abgerufenen Fördermittel der einzelnen Programme sind lediglich durch spezifische Anfragen beim jeweiligen Ansprechpartner der Bewilligungsstellen oder dem zuständigen Ministerium möglich.

Neben der großen Bandbreite an verschiedenen Förderprogrammen wird eine Übersichtlichkeit zusätzlich durch sich überschneidende Zeiträume der Förderrichtlinien erschwert. Die Förderprogramme beziehen sich zumeist auf einen Zeitraum von mehr als einem Jahr, sodass nicht notwendigerweise ein jährlicher Abruf von 100 Prozent das anzustrebende Optimum darstellt. An dieser Stelle ist zwischen den „klassischen" Förderprogrammen des Freistaats Sachsen und den aus den Strukturfonds der Europäischen Union, im Besonderen dem Europäischen Fonds für regionale Entwicklung (EFRE) sowie dem Europäischen Sozialfonds (ESF) finanzierten Förderprogrammen, zu unterscheiden. Die aus den europäischen Strukturfonds finanzierten Förderprogramme werden im Gegensatz zu den sächsischen Fördermittelprogrammen in 7-Jahresprogrammen ausgereicht. Demzufolge müssen zur Untersuchung der Fördermittelabrufe dieser aus den europäischen Strukturfonds finanzierten Förderprogramme im Grunde die Förderperioden anstatt einzelne Jahre analysiert werden. Dabei ergeben sich allerdings weitere Schwierigkeiten. Die vergangene Förderperiode 2007 bis 2013 ist nicht mit jener Förderperiode 2014 bis 2020 vergleichbar. Sowohl die Programmnamen als auch die Programminhalte der Förderrichtlinien ändern sich zum Teil im Zeitverlauf. Dadurch kommt es zu Verschiebungen oder sogar zum Auslaufen verschiedener Förderprogramme. Die verbleibenden Restmittel aus den entsprechenden Förderprogrammen werden folglich umgeschichtet und fließen in andere, bereits bestehende oder neue Förderprogramme ein. Zusätzlich werden häufig Ausgabereste in künftige Haushaltsjahre/Förderperioden oder andere Förderprogramme übertragen, da die Fördermittel innerhalb eines Haushaltsjahres oder einer mehrjährigen Förderperiode zumeist nicht vollständig ausgereicht werden. Dieses Problem besteht allerdings nicht nur bei den europäischen Strukturfonds sondern auch bei den sächsischen Förderprogrammen. Somit entsteht grundsätzlich bei allen Förderprogrammen häufig ein nachgelagerter Abfluss der Mittel. In einem Haushaltsjahr können dementsprechend durch verbleibende Ausgabereste aus Vorjahren neben den ursprünglich veranschlagten Mitteln deutlich mehr 
Mittel ausgereicht werden. Dementsprechend sind in den tatsächlichen Ausgaben eines Haushaltsjahres oder einer mehrjährigen Förderperiode zu einem gewissen Anteil ebenfalls Ansätze aus Vorjahren subsumiert. Durch diese Entwicklungen in der Fördermittelpraxis ist eine Zuordenbarkeit der veranschlagten und ausgereichten Mittel im Rahmen eines Förderprogramms in einem Haushaltsjahr bzw. einer Förderperiode nahezu ausgeschlossen. Folglich führt die Ermittlung von sogenannten Abrufquoten der verschiedenen Förderprogramme lediglich zu ungenauen Erkenntnissen und nicht zur Möglichkeit der Verifizierung oder Falsifizierung der eingangs aufgestellten These.

Zur Konkretisierung der aufgestellten These wird deshalb wiederum auf die Haushaltsrechnung des Freistaates Sachsen zurückgegriffen. Auf Basis der Übersicht zur Nachweisung der Ausgaben des Freistaates an den kommunalen Bereich können für alle betreffenden Haushaltsstellen Gesamtsoll, bestehend aus aktuellem Haushaltsbetrag sowie Vorjahresresten und Ist-Ergebnis bzw. verbliebener Rest gegenübergestellt und somit einerseits zur Verfügung stehende und andererseits verbleibende Mittel verglichen werden. Die Haushaltsrechnung ist hierbei unterteilt in eine Aufgliederung zum Kommunalen Finanzausgleich (KFA, Kapitel 1530) und eine Übersicht der Zuweisungen ohne das Kapitel 1530. Auch wenn die Mittelzuteilung innerhalb und außerhalb des KFA in der Regel auf Basis der gleichen Förderrichtlinien erfolgt, wird aus Gründen der Vereinfachung die Systematik der Haushaltsrechnung übernommen und nach Zuweisungen innerhalb und außerhalb des KFA differenziert.

Innerhalb des KFA entsprechen die investiven Zweckzuweisungen nach § 24 Finanzausgleichsgesetz den zu betrachtenden antragsgebundenen Fachförderprogrammen. Im Jahr 2015 waren hierfür 110 Millionen Euro vorgesehen. In Abbildung 1 ist das Gesamtsoll abgetragen, das zusätzlich zu dem für 2015 angesetzten Haushaltsbetrag 1110 Mio. Euro) auch die Vorjahresreste (ca. 80 Mio. Euro) beinhaltet. Daneben ist jeweils der verbliebene Rest abgebildet. Daraus resultieren je nach Förderbereich sehr unterschiedliche Abruf- bzw. Verbleibquoten. So sind für die Bereiche Schulhausbau, Wasserinfrastruktur und Straßenbau innerhalb des KFA zwar die höchsten Zuweisungen vorgesehen, gleichzeitig wurden hier jedoch im Jahr 2015 zweistellige Millionenbeträge nicht abgerufen. Insbesondere an den Zuweisungen für investive Maßnahmen im Bereich Wasserversorgung, Abwasserentsorgung, etc. lässt sich die Aufstauung der Mittel verdeutlichen: Die Höhe des Gesamtsolls (über 40 Mio. Euro) suggeriert zunächst, dass es sich um einen 
Förderschwerpunkt innerhalb des KFA handelt. Im Jahr 2015 waren allerdings nur Mittel in Höhe von 10 Millionen Euro neu angesetzt, über 75 Prozent des Gesamtsolls entfallen dagegen auf Vorjahresreste. Auch 2015 sind wiederum über 80 Prozent der zur Verfügung stehenden Mittel als verbliebener Rest ausgewiesen. Hohe Abrufquoten bzw. niedrige Verbleibquoten sind dagegen bei Zuweisungen für Denkmalschutz, Krankenhausbau und Brandschutz festzustellen.

\section{Abbildung 1: Investive Zweckzuweisungen innerhalb des KFA 2015 nach Aufgabenbereichen}

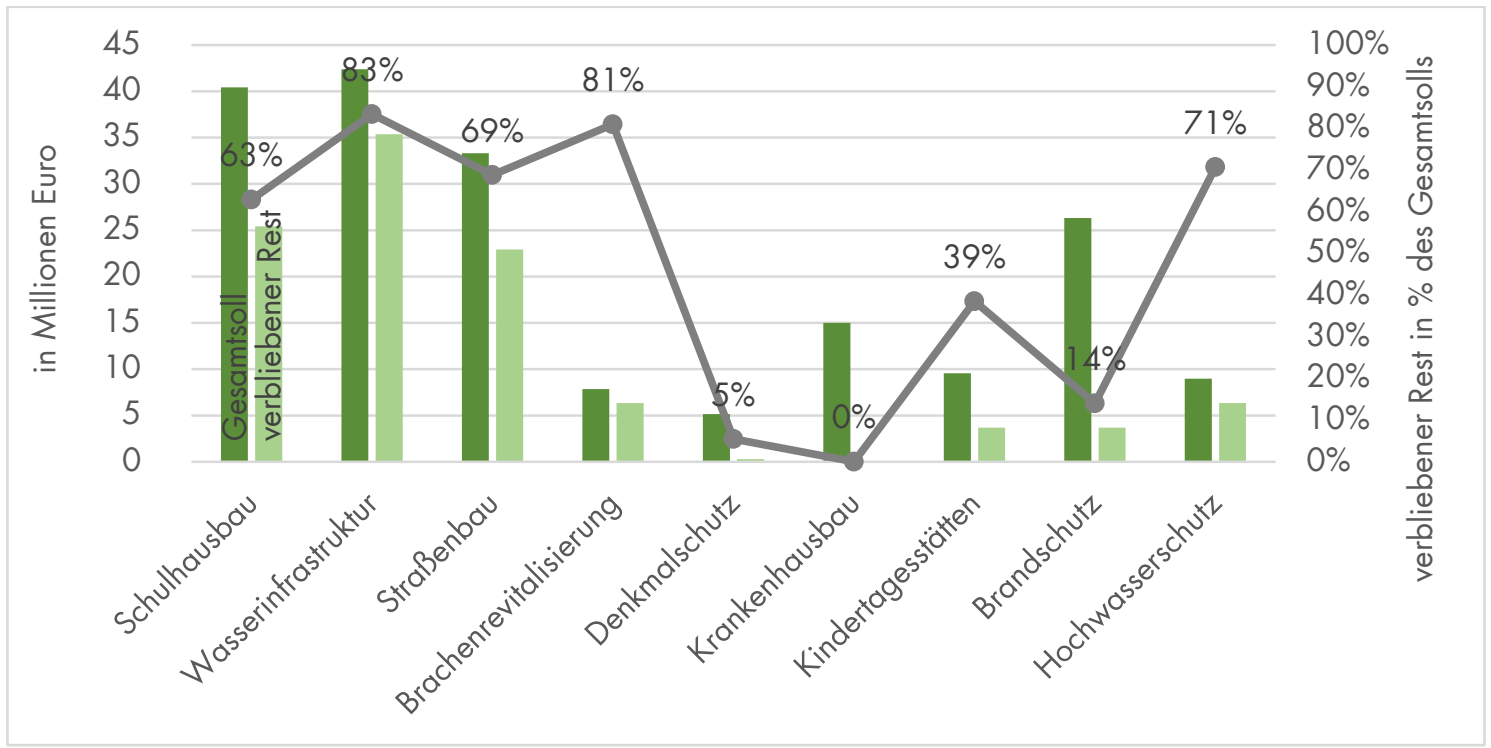

Quelle: Eigene Darstellung, Daten: Haushaltsrechnung 2015 des Freistaates Sachsen.

Außerhalb des KFA ist die Zuweisungsstruktur deutlich komplexer und entsprechend unübersichtlicher. Vor dem Hintergrund wird hier nur die Summe der investiven Zuweisungen an die Gemeinden und Gemeindeverbände (Gruppierung 883) von 2009 bis 2015 betrachtet und wiederum dem jeweils verbliebenen Rest gegenübergestellt. In dieser Summe sind u.a. die EU-Programme EFRE, ESF und ELER, Bund-Länder-Programme, bspw. zur Städtebauförderung, sowie Landesprogramme wie die "Digitale Offensive Sachsen" enthalten. Aus Abbildung 2 geht hervor, dass (vom negativen Ausreißer 2009 abgesehen) regelmäBig um die 40 Prozent der Zuweisungen als Rest verbleiben. Bemerkenswert ist auch, dass die Summe der vorgesehenen investiven Zuweisungen seit 2010 kontinuierlich zurückgegangen ist. Dies ist zwar einerseits auf erhöhte Zuweisungen im Rahmen des Konjunkturpakets II und infolge des Hochwassers 2010 zurückzuführen. Ebenso spiegeln sich die abschmelzenden Solidarpaktmittel in dem negativen Trend wider. Dennoch ist zumindest die Frage zu stellen, ob auch der unzureichende Mittelabruf zu einer Abschmelzung der bereitgestellten Fördermittel beigetragen hat. 
Abbildung 2: $\quad$ Summe investiver Zuweisungen an Gemeinden außerhalb des KFA 2009-2015

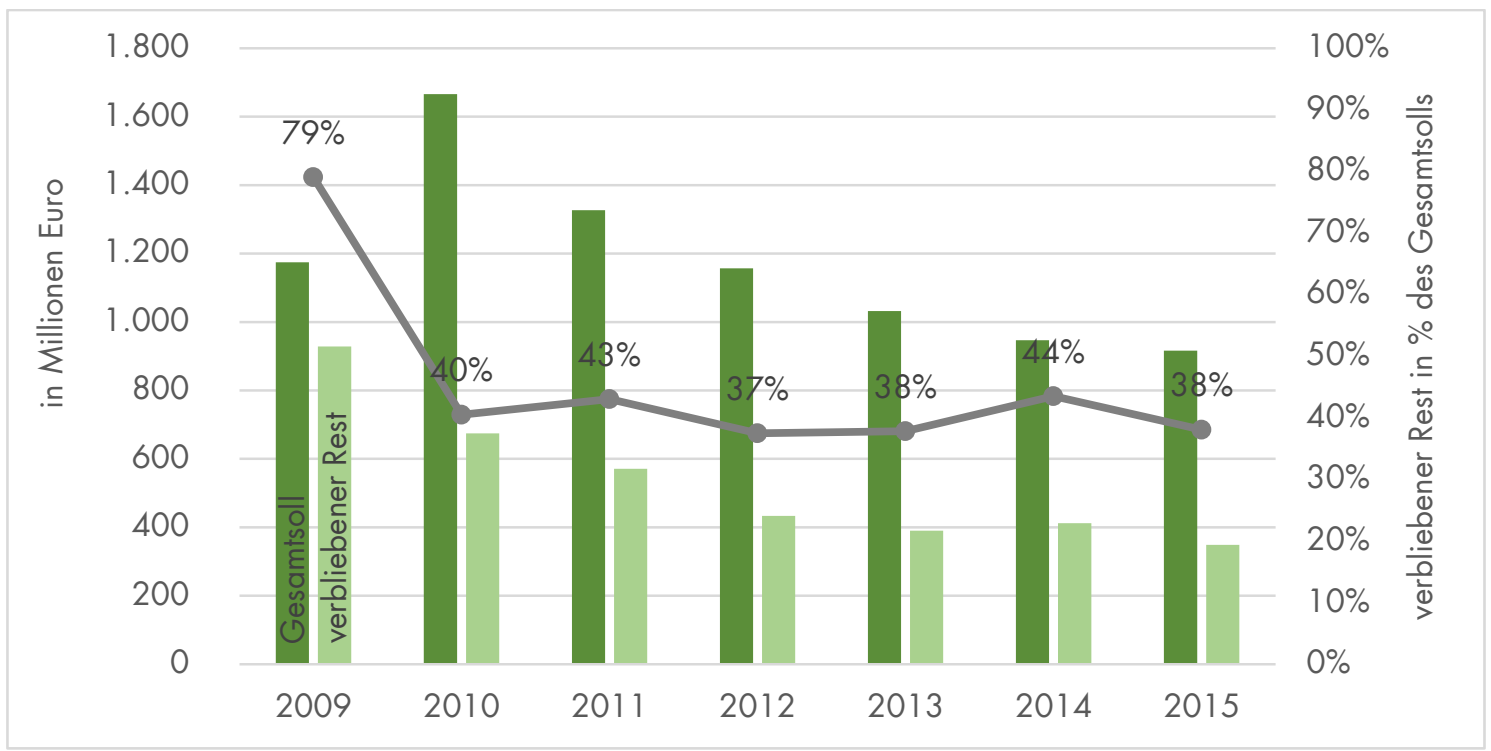

Quelle: Eigene Darstellung, Daten: Haushaltsrechnung 2015 des Freistaates Sachsen.

Exemplarisch für die Zuweisungen außerhalb des KFA wird die Förderrichtlinie zur Verbesserung der schulischen Infrastruktur betrachtet. Diese war im Jahr 2015 für verschiedene Haushaltstitel maßgeblich (u.a. auch für die Zuweisung innerhalb des KFA). Ein Blick in die Haushaltsrechnung zeigt, dass hier zusätzlich zu den verbleibenden 25 Millionen Euro innerhalb des KFA im Jahr 2015 außerhalb des KFA mit knapp 50 Millionen Euro noch einmal doppelt so viele Mittel nicht abgerufen wurden. Auch beim kommunalen StraBen- und Brückenbau sind nochmals über 50 Millionen Euro verblieben. Am aktuellen Rand ist hier nach Angaben des Landesamtes für Straßenbau und Verkehr, der zuständigen Bewilligungsbehörde, jedoch ein deutlich erhöhter Abruf der zur Verfügung stehenden Mittel zu beobachten. Als Begründung für den verbesserten Mittelabruf wurde eine Novellierung der maßgeblichen Förderrichtlinie im vergangenen Jahr angeführt.

Zusammenfassend lässt sich jedoch die eingangs aufgestellte These insoweit bestätigen, als dass der Mittelabruf zumindest nicht optimal verläuft. Die Ergebnisse der Haushaltsrechnung haben gezeigt, dass regelmäßig Millionenbeträge nicht abgerufen werden. Vor dem Hintergrund werden im nachfolgenden Kapitel mögliche Ursachen und Herausforderungen identifiziert, um anknüpfend daran potenzielle Handlungsfelder zur Beschleunigung des Mittelabrufs zu benennen. 


\section{Herausforderungen bei der Förderung kommunaler Infrastrukturprojekte}

Im nachfolgenden Kapitel sollen die Herausforderungen bei der Förderung kommunaler Infrastrukturprojekte analysiert werden. Hierzu werden verschiedene Thesen darüber aufgestellt, welche Umstände oder Anforderungen im Förderprozess zu einer Verzögerung des Mittelabrufs beitragen könnten. Die aufgestellten Thesen gilt es anschließend im Hinblick auf ihre Relevanz zu prüfen und einzuordnen.

Zur Einordnung der Thesen werden u.a. die im Rahmen der KOMKIS Dialogveranstaltung „Förderprogramme - Fluch oder Segen?" im März 2017 aufgetretenen Diskussionspunkte berücksichtigt, an der Vertreter von Kommunen und Spitzenverbänden, Landesministerien und -ämtern, der Sächsischen Aufbaubank und des Sächsischen Rechnungshofes teilgenommen haben. Weiterhin werden die Ergebnisse einer im ersten Halbjahr 2016 vom KOMKIS durchgeführten Befragung der sächsischen Städte, Gemeinden und Landkreise verwendet. Dabei wurden neben kommunalen Investitionsbedarfen auch Erfahrungen und Herausforderungen im Zusammenhang mit Förderprogrammen abgefragt. Vor dem Hintergrund einer Rücklaufquote von knapp 25 Prozent und der Einwohnergrößenstruktur der Stichprobe im Vergleich zur Grundgesamtheit aller Kommunen im Freistaat Sachsen sind repräsentative Auswertungen der Ergebnisse und die Ableitung allgemeingültiger Aussagen möglich. ${ }^{47}$

Die Analyse der Thesen erfolgt nach drei Kategorien:

1. Informations- und Zuständigkeitsprobleme,

2. Ausgestaltung der Förderprogramme sowie

3. Förderprozessumsetzung bzw. -abwicklung.

47 Der Stichprobenfehler ist die zentrale Messgröße zur Bewertung der statistischen Abweichung einer Stichprobe von der Grundgesamtheit. Ein geringer Stichprobenfehler spricht für eine große Übereinstimmung zwischen Stichprobe und Grundgesamtheit. Dieser liegt bei Zugrundlegung eines Vertrauensintervalls von $95 \%$ bei maximal 8,5\%. Wird ein Vertrauensintervall von $90 \%$ vorausgesetzt, liegt er bei rund 7,0\%. Dies wird für die Beantwortung der Fragen des Fragebogens, die sich häufig auf Abschätzungen und Meinungsäußerungen beziehen, als hinreichend erachtet. Vgl. hierzu auch Kilian/Hesse/Redlich (2016). Daher können die aus der Befragung gewonnenen Erkenntnisse auf die Gesamtheit der sächsischen Kommunen übertragen werden. 


\subsection{Informations- und Zuständigkeitsprobleme}

Zunächst sollen unter dieser Kategorie jene Aspekte beleuchtet werden, die im Vorfeld des Förderprozesses zu hohen Transaktionskosten, insbesondere Informationskosten führen. In diesem Zusammenhang soll geklärt werden, wie über die verschiedenen Förderprogramme informiert und wie die Verfügbarkeit der relevanten Informationen eingeschätz† wird, bei wem die Förderanträge gestellt werden und wer diese anschließend bewilligt.

\section{These 1: Der Informationsaufwand, um ein geeignetes förderprogramm zu finden, ist zu hoch.}

Diese These wird zum einen damit begründet, dass es zu viele verschiedene Förderprogramme für jeweils einen Fördergegenstand gebe. Zum anderen erscheinen die Instrumente zur Erleichterung der Suche nicht ausgereift.

Um die Kommunen und andere potenzielle Zuwendungsempfänger bei der Suche nach einem geeigneten Förderprogramm zu unterstützen, unterhält der Freistaat Sachsen eine eigene Fördermitteldatenbank sowie eine Datenbank, in der alle sächsischen Rechtsvorschriften (entsprechend auch Förderrichtlinien) aufgeführt sind. ${ }^{48}$ Hierbei sind die Angaben zum Teil nicht aktuell oder auch widersprüchlich. ${ }^{49}$ Zusätzlich unterhält auch das Bundesministerium für Wirtschaft und Energie eine Förderdatenbank, in der Förderprogramme und Finanzhilfen des Bundes, der Länder und der EU zusammengefasst werden. ${ }^{50}$ Während die übrigen Bundesländer diese Bundesdatenbank nutzen, unterhält der Freistaat Sachsen eine eigene Fördermitteldatenbank, in der aber bspw. nicht alle Bundesprogramme aufgeführt sind. Es bleibt festzuhalten, dass grundsätzlich keine einheitliche Datenbank existiert, in der alle potenziellen Förderprogramme für (sächsische) Kommunen und weitere Zuwendungsempfänger vollständig aufgeführt sind. Daher besteht für sächsische Kommunen die Notwendigkeit, sich bei mehreren Ansprechpartnern und Datenbanken (Fömisax-Fördermitteldatenbank Sachsen, SAB, Förderdatenbank zu Förderprogrammen und Finanzhilfen des Bundes, der Länder und der EU) zu informieren. Dies ist zumeist

\footnotetext{
${ }^{48}$ Die Suche geeigneter Förderrichtlinien wird in der FÖMISAX-Fördermitteldatenbank Sachsen unter dem Reiter Förderlotse mittels verschiedener Unterförderbereiche, wie z. B. Bildung oder Gesundheits- und Sozialwesen erleichtert. Innerhalb dieser Unterförderbereiche besteht nochmals die Möglichkeit, die Suche durch weitere Unterkategorien zu verfeinern.

${ }^{49} \mathrm{Vgl}$. hierzu auch Plaza (2016).

${ }^{50} \mathrm{Vgl}$. Bundesministerium für Wirtschaft und Energie (2017).
} 
allerdings mit einem höheren zeitlichen Aufwand verbunden als die Recherche in einer einzigen Datenbank.

Abbildung 3: Bekanntheitsgrad und Nutzung ausgewählter Förderprogramme

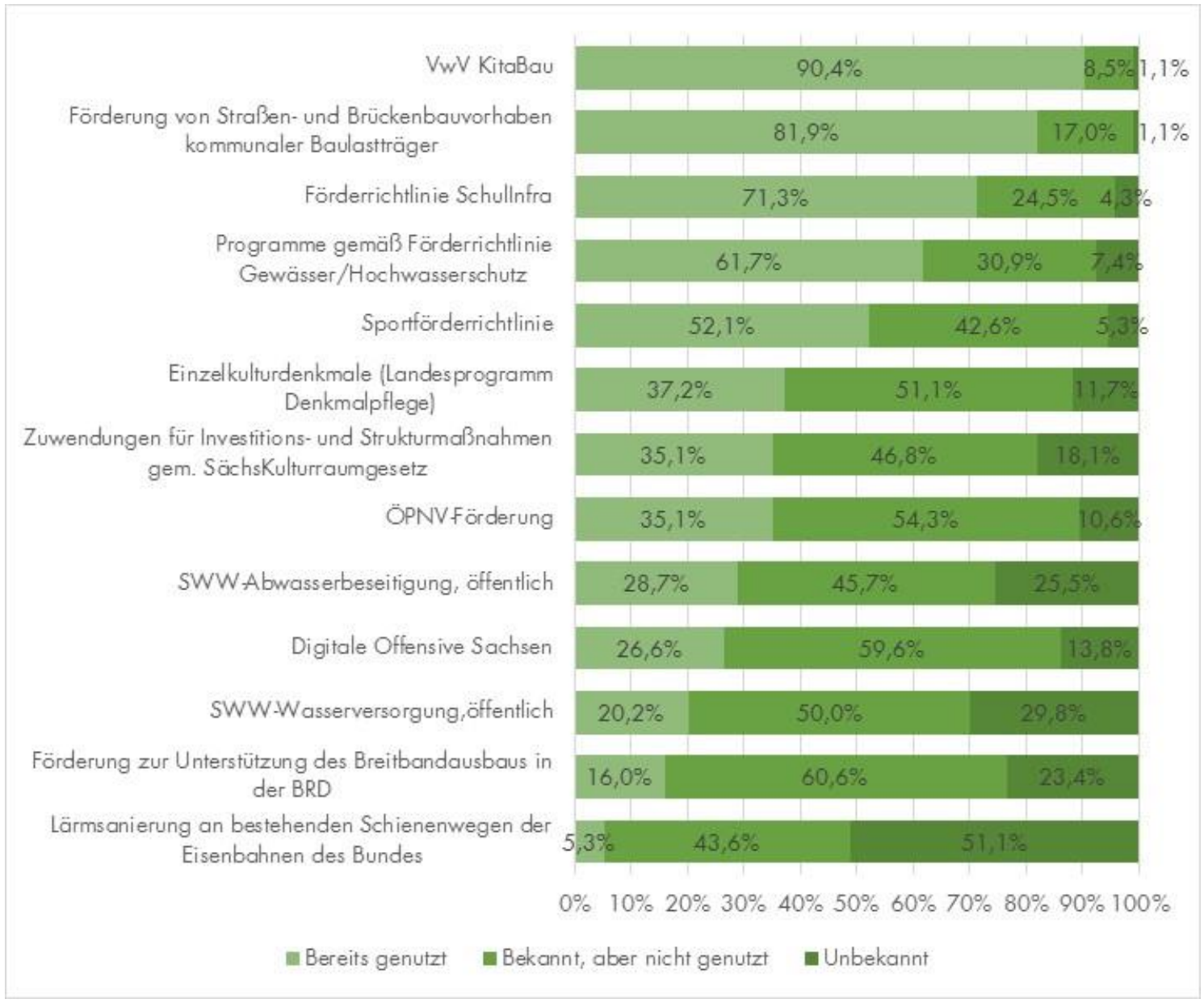

Quelle: Eigene Erhebung ( $\mathrm{n}=94)$, eigene Darstellung.

Trotz dieser erschwerten Bedingungen bei der Suche nach einem geeigneten Förderprogramm sind aber die wichtigsten Förderrichtlinien aus dem Bereich Kita, Verkehrsinfrastruktur und Schulhausbau überwiegend nicht nur bekannt, sondern auch bereits genutz† worden, wie Abbildung 3 zeigt. Den höchsten „Unbekanntheitsgrad" mit über 50 Prozent weist das Programm „Lärmsanierung an bestehenden Schienenwegen der Eisenbahnen des Bundes" und damit ein sehr spezielles Bundesprogramm auf.

Im Rahmen der Befragung der sächsischen Kommunen in 2016 wurde hinsichtlich der Hindernisse bei der Nutzung von Förderprogrammen zusätzlich deutlich, dass die Mehrheit der befragten Kommunen (54,2 \%) den Informationsaufwand im Rahmen der Suche nach geeigneten Förderprogrammen als zu hoch einschätzt. Dennoch wurden ebenfalls 
durch die Mehrheit der befragten Kommunen (55,3 \%) die Websites, auf denen Informationen über die Förderprogramme gegeben werden, eher als benutzerfreundlich und übersichtlich beurteilt. Lediglich rund ein Drittel der befragten Kommunen kritisierte deren Übersichtlichkeit und Benutzerfreundlichkeit. Dieses eher ambivalente Ergebnis wird ebenso bei der Frage zur Programmvielfalt deutlich, welche durch 40,4 \% der befragten Kommunen als zu groß erachtet wird. Hingegen empfindet die Mehrheit der befragten Kommunen $(54,2 \%)$ die Programmvielfalt nicht als zu groß.

\section{Abbildung 4: Befragungsergebnisse zu These 1}

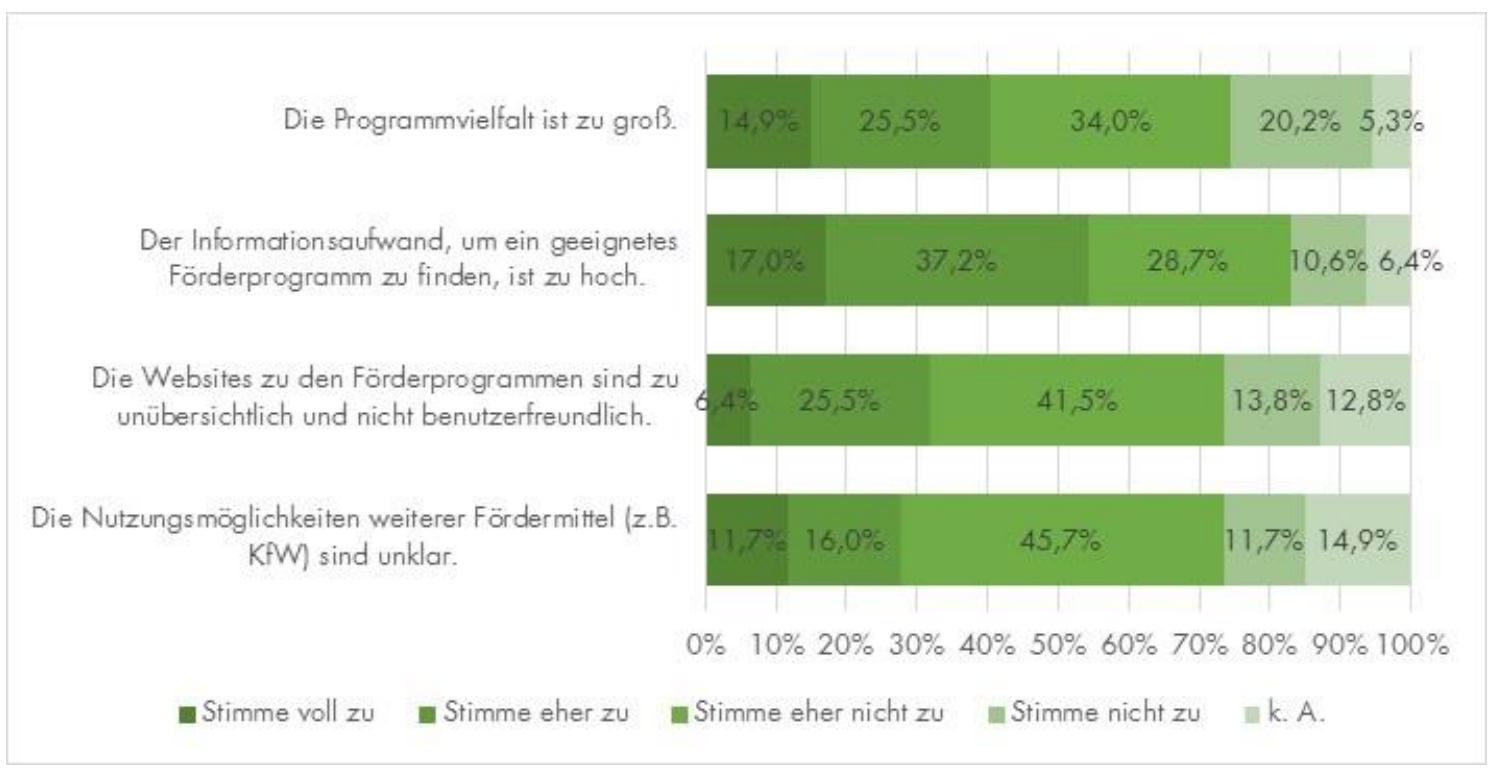

Quelle: Eigene Erhebung ( $n=94)$, eigene Darstellung.

Durch das Befragungsergebnis wird ersichtlich, dass der mit der Suche nach geeigneten Förderprogrammen verbundene hohe Informationsaufwand weniger auf die mangelnde Verfügbarkeit der Informationen zurückzuführen ist. Insbesondere die komplizierten Förderrichtlinien sowie die große Anzahl an verschiedenen Ansprechpartnern für die jeweiligen Förderprogramme erschweren die Übersichtlichkeit und den daraus resultierenden Informationsaufwand. Dies wird mit der folgenden These 2 nochmals deutlich.

\section{These 2: Zahlreiche Ansprechpartner und je nach Programm variierende Bewilligungsstellen erschweren die Übersicht.}

Diese These war keine der im Fragebogen angebotenen Antwortoptionen, wurde jedoch durch die befragten Kommunen im Freitext mehrfach genannt. Als Konsequenz wurden häufig einheitliche Ansprechpartner gefordert. Hierzu ist anzumerken, dass bereits ein Großteil der Förderprogramme über die Sächsische Aufbaubank abgewickelt wird. 
Gleichwohl bestehen nach wie vor Ausnahmen, die den Förderprozess im Vorfeld verkomplizieren.

Insgesamt führen Informations- und Zuständigkeitsprobleme offenbar nicht zu einem Verzicht auf Fördermittel, sondern erschweren allenfalls den Fördermittelzugang und können damit den Prozess verzögern (Transaktionskosten). Auf Basis des Dialogs und der Kommunalbefragung lässt sich aber nicht feststellen, dass Schwierigkeiten dieser Kategorie zu einem vollständigen Verzicht auf Fördermittel führen. Der unzureichende Abruf der Fördermittel lässt sich damit folglich nur bedingt erklären.

\subsection{Ausgestaltung der Förderprogramme}

Im Gegensatz zu der vorhergehenden Kategorie, in der die im Vorfeld eines Förderprozesses bestehenden Herausforderungen untersucht wurden, sollen im Folgenden mögliche Ursachen und Herausforderungen beleuchtet werden, welche in der Konstruktion der Förderprogramme begründet liegen.

\section{These 3: Die Förderprogramme sind nicht bedarfsgerecht.}

Wenngleich die Förderschwerpunkte zumindest die Bedarfsschwerpunkte weitestgehend decken, ${ }^{51}$ besteht vielfach die Forderung nach flexibleren Einsatzmöglichkeiten der Fördermittel. Diese bisher stark begrenzte Gestaltungsfreiheit der Kommunen führt zwar nicht zu einer Verringerung des Fördermittelabrufs (siehe Abbildung 5), schränkt die Kommunen jedoch zum Teil sichtlich in ihrer Prioritätensetzung und Realisierung bedarfsorientierter Maßnahmen ein.

\section{Abbildung 5: Befragungsergebnisse zu These 3}

Die Programme sind nicht geeignet, da in den

"falschen" kommunalen Bereichen gefördert wird.

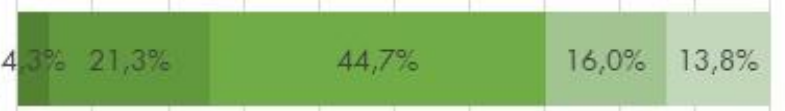

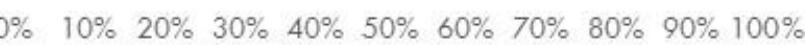

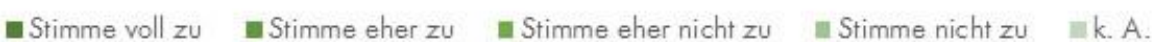

Quelle: Eigene Erhebung ( $n=94)$, eigene Darstellung.

${ }^{51} \mathrm{Vgl.} \mathrm{Kilian/Hesse/Redlich} \mathrm{(2016),} \mathrm{S.} 18$. 
Folglich werden durch die Förderprogramme entsprechende Investitionsschwerpunkte gesetzt. Somit kann vermutet werden, dass Kommunen ihre zu realisierenden Maßnahmen und Projekte entsprechend weniger nach dem aktuell drängendsten Bedarf und eher nach den aktuell verfügbaren Fördermitteln und Fördermöglichkeiten auswählen.

Grundsätzlich sollte bei einem idealtypischen Förderprozess die Ermittlung des Bedarfs einer Kommune noch vor der Auswahl eines geeigneten Förderprogramms an erster Stelle stehen. Da sich diese Reihenfolge im realen Förderprozess allerdings bei steigender Relevanz der Verfügbarkeit von Fördermitteln für die Infrastrukturbeschaffung tendenziell umkehrt, bleibt zu vermuten, dass Kommunen primär verfügbare Fördermittel recherchieren, um ihre Infrastrukturprojekte gezielt auf diese entsprechenden Förderrichtlinien zuzuschneiden.

\section{These 4: Es werden primär investive Maßnahmen, aber kaum Instandhal- tungsmaßnahmen gefördert.}

Den Befragungsergebnissen zufolge stellen die geringen Möglichkeiten der Förderung von Erhaltungsmaßnahmen in die vorhandene Infrastruktur eines der größten Probleme dar. Die überwiegende Mehrheit der befragten Kommunen (99\%) gab an, dass fast ausschließlich Investitionen und weniger Erhaltungsmaßnahmen gefördert werden (vgl. Abbildung 6). Hingegen schätzte lediglich ein Viertel der befragten Kommunen die Förderprogramme aufgrund der Förderung "falscher" Ausgabearten als ungeeignet ein. Dieses Ergebnis unterstreicht zum Teil die vorangegangene These, da die Förderprogramme an dieser Stelle von den Kommunen nicht als ungeeignet beurteilt werden, wenngleich der Bedarf nach der Förderung von Erhaltungsmaßnahmen derzeit teilweise größer ist als jene Förderung von (zusätzlichen) Investitionsmaßnahmen.

Der Problematik geringer Fördermöglichkeiten von Erhaltungsaufwendungen wird allerdings zunehmend entgegengewirkt. Dies zeigt sich beispielsweise an dem sächsischen Fördermittelprogramm „Brücken in die Zukunft". Dieses Sondervermögen in Höhe von 800 Millionen Euro, welches im Rahmen des Gesetzes zur Stärkung der kommunalen Investitionskraft errichtet worden ist, wird den sächsischen Kommunen nicht nur zur Finanzierung 
von Investitions- sondern auch von Instandhaltungs- bzw. Erhaltungsmaßnahmen in die kommunale Infrastruktur ausgereicht. ${ }^{52}$

\section{Abbildung 6: Befragungsergebnisse zu These 4}

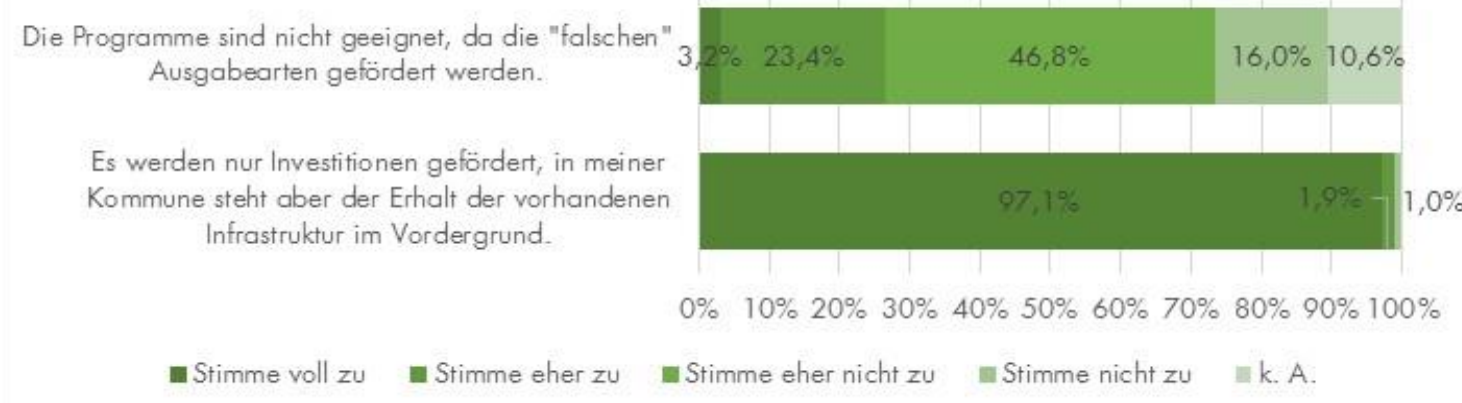

Quelle: Eigene Erhebung ( $\mathrm{n}=94)$, eigene Darstellung.

Im Rahmen der KOMKIS-Dialogveranstaltung "Förderprogramme - Fluch oder Segen?" wurde das Beispiel des Fördermittelprogramms „Brücken in die Zukunft” und der Gedanke, verstärkt künftige Fördermöglichkeiten für Erhaltungsaufwendungen nach diesem Vorbild zu schaffen, mit Vertretern der Landesministerien diskutiert. Dabei merkten diese an, dass bei Instandhaltungsmaßnahmen häufig die Bagatellgrenze unterschritten werde. Das führe dazu, dass das Verfahren bzw. die Abwicklung des Förderprozesses auf Landesebene häufig mehr finanzielle Mittel in Anspruch nimmt als das originäre Fördervolumen für die Instandhaltungsmaßnahme.

\section{These 5: Die Förderquote ist zu gering bzw. der Eigenanteil ist zu hoch.}

Zur Auseinandersetzung mit der These, die Förderquoten für kommunale Infrastrukturprojekte seien zumeist zu gering bzw. sei der kommunale Eigenanteil häufig insbesondere für finanzschwächere Kommunen zu hoch, gilt es zunächst die Notwendigkeit eines kommunalen Eigenanteils bei Förderprogrammen zu klären.

Die Beteiligung der Kommune an der Finanzierung kommunaler Infrastrukturprojekte hat zwei zentrale Ziele. Einerseits sollten die Kommunen ein Eigeninteresse an einer effizienten Aufgabenerbringung haben. Im Rahmen der Realisierung bevorstehender kommunaler Infrastrukturprojekte sollten dementsprechend Wirtschaftlichkeitsuntersuchungen an Bedeutung gewinnen. Andererseits sollen durch kommunale Eigenbeteiligungen Mitnahmeeffekte

\footnotetext{
${ }^{52}$ Vgl. § 1 Sächsisches Investitionskraftstärkungsgesetz.
} 
reduziert bzw. gänzlich vermieden werden. Diese treten unter folgenden zwei Voraussetzungen auf:

1. Eine Kommune beantragt die Förderung jener Investitionen, welche ohnehin getätigt worden wäre, um von den zur Verfügung stehenden Fördermitteln zu profitieren (Mitnahmeeffekt). ${ }^{53}$

2. Eine Kommune beantragt die Förderung einer Investition ohne Berücksichtigung von Bedarfen, regionaler Anforderungen und Prioritäten. Entsprechend könnten durch die Kommune Infrastrukturprojekte innerhalb des verfügbaren Förderumfangs "kreiert" werden, um jene Fördermittel zu erlangen ("Hebeln” von Eigenmitteln)..$^{54}$

Durch solche Effekte werden die mit den Förderrichtlinien angestrebten Ziele wie bspw. investive sowie zusätzliche Impulse für Wachstum und Beschäftigung zu setzen oder bestehende bzw. zunehmende Investitionslücken zu schließen und dem Investitionsstau entgegenzuwirken, zumeist verfehlt. ${ }^{55}$ Um diesen Auswirkungen vorzubeugen, dienen Eigenbeteiligungen der Kommunen an kommunalen Infrastrukturprojekten, welche den Fokus zunehmend auf bedarfsorientierte und effiziente Projekte legen.

\section{Abbildung 7: Befragungsergebnisse zu These 5}

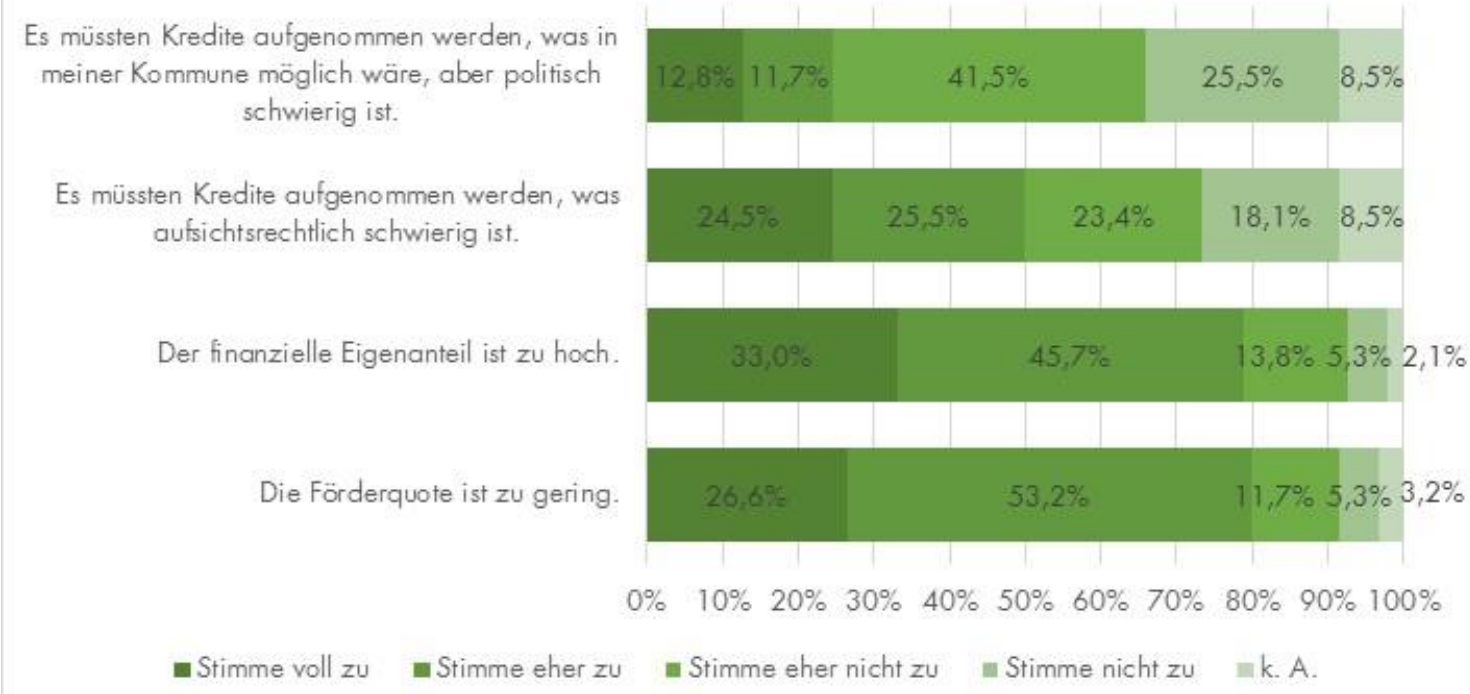

Quelle: Eigene Erhebung ( $n=94)$, eigene Darstellung.

${ }^{53} \mathrm{Vgl}$. Zimmermann (2009), S. $218 \mathrm{f}$.

${ }^{54} \mathrm{Vgl}$. Lenk/Hesse/Kratzmann (2017), S. 169.

${ }^{55} \mathrm{Vgl}$. Kratzmann/Redlich/Hesse (2016), o. S.; Lenk/Hesse/Kratzmann (2017), S. 169. 
Im Rahmen der Befragung wurde mehrheitlich deutlich, dass die befragten Kommunen die Förderquoten als zu gering empfinden. Die überwiegende Mehrheit der befragten Kommunen hält, wie in Abbildung 7 ersichtlich, die Förderquote generell für zu niedrig $(79,8 \%)$ und korrespondierend dazu den finanziellen Eigenanteil der Kommunen für zu hoch $(78,7 \%)$. Zudem spiegelt sich die geringe Förderquote bzw. der hohe kommunale Eigenanteil indirekt in der Rückmeldung der befragten Kommunen hinsichtlich der Notwendigkeit von Kreditaufnahmen zur Finanzierung entsprechender Projekte wider. In diesem Zusammenhang meldete jede zweite befragte Kommune aufsichtsrechtliche oder politische Schwierigkeiten bezüglich der Möglichkeit einer Kreditaufnahme als Alternative zu Fördermitteln zum Zweck der Finanzierung kommunaler Infrastrukturmaßnahmen.

Im Hinblick auf die These, der kommunale Eigenbeitrag sei zu hoch, wurden in der Befragung allerdings Unterschiede zwischen bevölkerungsstärkeren und bevölkerungsschwächeren Kommunen deutlich. Die folgende Abbildung 8 verdeutlicht die relative Zustimmung zu dieser Aussage nach Einwohnerklassen differenziert. Im Rahmen dieser Betrachtung wird die mit steigender Einwohnerklasse tendenziell sinkende Zustimmung zur Eigenanteilsproblematik evident. Während die Kommunen bis unter 3.000 Einwohner der These, der Eigenanteil sei zu hoch, überwiegend zustimmen $78,7 \%$ der Befragten stimmten eher bis voll zu), liegt der Anteil der Kommunen mit 20.000 Einwohnern und mehr mit 62,5\% spürbar darunter.

\section{Abbildung 8: Befragungsergebnisse zum Eigenanteil nach Einwohnerklassen}

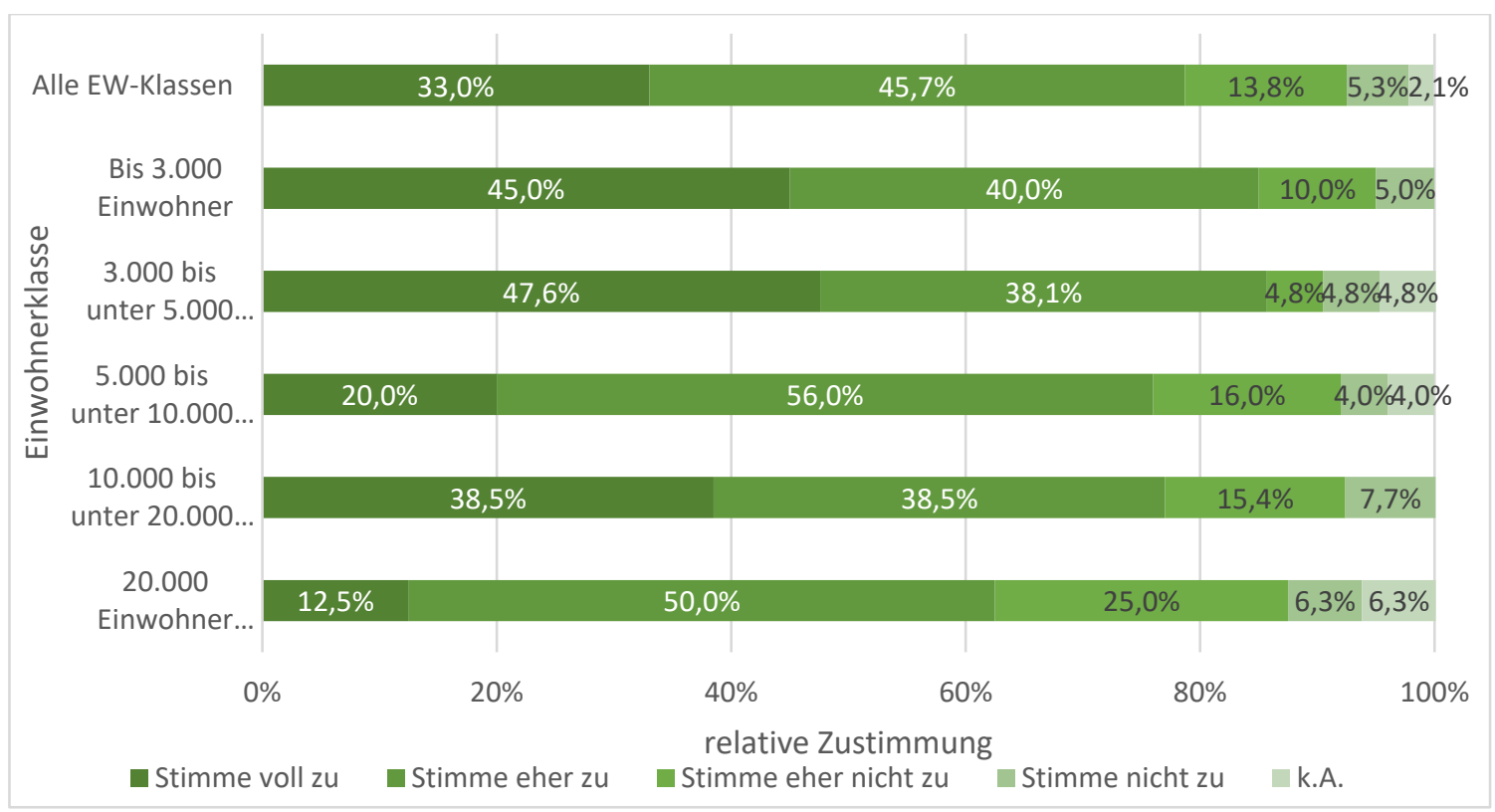

Quelle: Eigene Erhebung ( $\mathrm{n}=95)$, eigene Darstellung. 
Die Analyse einiger tatsächlicher Förderquoten im Zeitverlauf verdeutlicht allerdings einen tendenziell steigenden Trend. Sowohl die Steigerung der Förderquote der Förderrichtlinie Straßen- und Brückenbauvorhaben kommunaler Baulastträger von 75 \% der zuwendungsfähigen Kosten in 2008 und 2012 auf nach Kostenträgern differenzierte Förderquoten bis zu 100 \% (für Eisenbahnkreuzungen) im Jahr 2015, als auch jene der Sportförderrichtlinie von 30 \% der förderfähigen Aufwendungen im Jahr 1997 und 2003 auf 50 \% der zuwendungsfähigen Ausgaben bei gedeckten Sportstätten in den Jahren 2007 sowie 2009 unterstreichen dies.

Aus der Sicht der Landesregierung kann vor dem Hintergrund der bereits dargelegten theoretischen Gründe allerdings nachvollzogen werden, dass grundsätzlich ein Eigenbeitrag zur Finanzierung von Infrastrukturmaßnahmen durch die Kommunen geleistet werden soll. Die Beschaffung der dafür notwendigen Mittel sollte im Allgemeinen kein Problem für die Kommunen darstellen. Insbesondere die Befragungsergebnisse verweisen allerdings darauf, dass die Finanzierung des Eigenanteils die Kommunen, vor allem finanz- oder einwohnerschwächere Kommunen, häufig vor Probleme stellt. Es besteht folglich die Gefahr, dass insbesondere jene Kommunen, welche eine Förderung am dringendsten benötigen würden, aufgrund des Eigenanteils nicht von den zur Verfügung stehenden Fördermitteln profitieren können.

\section{Grundsätzliche Ausgestaltung der Förderprogramme}

Generell sollte hinsichtlich der Ausgestaltung der Förderprogramme berücksichtigt werden, dass die Fördermittellandschaft nicht nur aus langfristigen, fortlaufenden Förderprogrammen besteht, sondern ebenfalls aus zeitlich begrenzten Förderinitiativen von Bund und Ländern. Letztere verfügen häufig über große Volumina, welche zumeist kurzfristig abgerufen werden müssen. Ein aktuelles Beispiel stellt das derzeitige Schulhausbauprogramm des Bundes dar (2018). Zur Steigerung der Investitionstätigkeit in die kommunale Schulinfrastruktur hat dieser den Kommunalinvestitionsförderungsfond im Anschluss an die BundLänder-Einigung über die umfängliche Neuordnung ihrer Finanzbeziehungen im Oktober 2017 um 3,5 Milliarden Euro aufgestockt. Mit dieser bis zum Jahr 2020 begrenzten Förderinitiative strebt der Bund eine Verbesserung der finanziellen Lage der kommunalen Ebene zum Ziel der Deckung des Investitionsbedarfs in die Schulinfrastruktur an. ${ }^{56}$

${ }^{56} \mathrm{Vgl}$. Lenk/Hesse/Kratzmann (2017), S. $172 f$. 
In den vergangenen Jahren standen im Rahmen der bestehenden Förderrichtlinien insgesamt deutlich weniger Fördermittel zur Verfügung, sodass insbesondere die personellen Planungs- und Begleitungskapazitäten in den kommunalen Bauverwaltungen im Zeitverlauf abgebaut wurden. ${ }^{57}$ Durch einen kurzfristig und zeitlich begrenzten bzw. punktuellen Anstieg der von Bund und/oder Land zur Verfügung gestellten Fördermittel, entsteht für Kommunen das Problem der für einen entsprechenden Mitteleinsatz notwendigen Verfügbarkeit langfristig zu planender Kapazitäten. Folglich wird von kommunaler Seite die Volatilität der Mittelverfügbarkeit in verschiedenen Perioden als Problem benannt und eine Verstetigung des Mittelzuflusses gefordert.

\subsection{Förderprozessumsetzung/-abwicklung}

Der folgende Abschnitt beschäftigt sich mit den Herausforderungen, welche während eines Förderprozesses auftreten. Diese sind primär organisatorischer Art und stellen im Gegensatz zu den im vorherigen Abschnitt beleuchteten Herausforderungen im Rahmen der Ausgestaltung der einzelnen Förderprogramme jene allgemeinen Probleme bei der Beantragung und der Vergabe der Fördermittel dar. Die Rechtsgrundlagen für die Abwicklung der Förderprogramme stellen in der Regel die Förderrichtlinien dar, welche sich an der Verwaltungsvorschrift zu § 44 SäHO orientieren (vgl. Abschnitt 1.3).

\section{These 6: Der Arbeits- und Dokumentationsaufwand im Rahmen eines För- derantrags ist zu hoch. Außerdem sind die Beantragungs- bzw. Abruffristen zu knapp bemessen.}

Sowohl im Rahmen der im März 2017 durchgeführten Dialogveranstaltung als auch in der Befragung der sächsischen Kommunen im Jahr 2016 wurde deutlich, dass der zur Beantragung von Fördermitteln notwendige Arbeitsaufwand für die Kommunen als verhältnismäßig hoch eingeschätzł wird. Dieser nimmt darüber hinaus im Zeitverlauf aufgrund kleinteiliger und komplizierter werdender Richtlinien bzw. Auflagen stetig zu. Diese Entwicklung erklärt sich dadurch, dass die in einem Förderprozess gegebenenfalls auftretenden Regelungslücken durch die zuständigen Ministerien unverzüglich zu schließen sind. Dadurch steigt die Anzahl kleinteiliger Regelungen, Auflagen und Richtlinien, sodass der

${ }^{57}$ Zum bremsenden Effekt der Engpässe bei den Verwaltungskapazitäten auf die Investitionen vgl. Gornig/Michelsen (2017). 
Arbeits- und Dokumentationsaufwand sowohl auf der Seite des Fördermittelgebers als auch des Fördermittelnehmers deutlich zunimmt.

Dementsprechend kompliziert erscheinen die zum Teil zu modifizierenden Förderrichtlinien sowie die Beantragung und Vergabe der entsprechenden Mittel. Diese Einschätzung wurde ebenfalls in der Befragung der Kommunen, insbesondere der kleineren Kommunen deutlich. Abbildung 9 veranschaulicht, dass eine große Mehrheit der befragten Kommunen $(69,2 \%)$ der These, die Förderrichtlinien seien zu kompliziert, eher bis voll zustimmt. Zudem bestätigte sich die eingangs aufgestellte These, dass der im Vorfeld einer Förderung bestehende Arbeitsaufwand von der überwiegenden Mehrheit der befragten Kommunen $(73,4 \%)$ als Hindernis im Rahmen der Fördermittelbeantragung wahrgenommen wird.

\section{Abbildung 9: Befragungsergebnisse zu These 6}

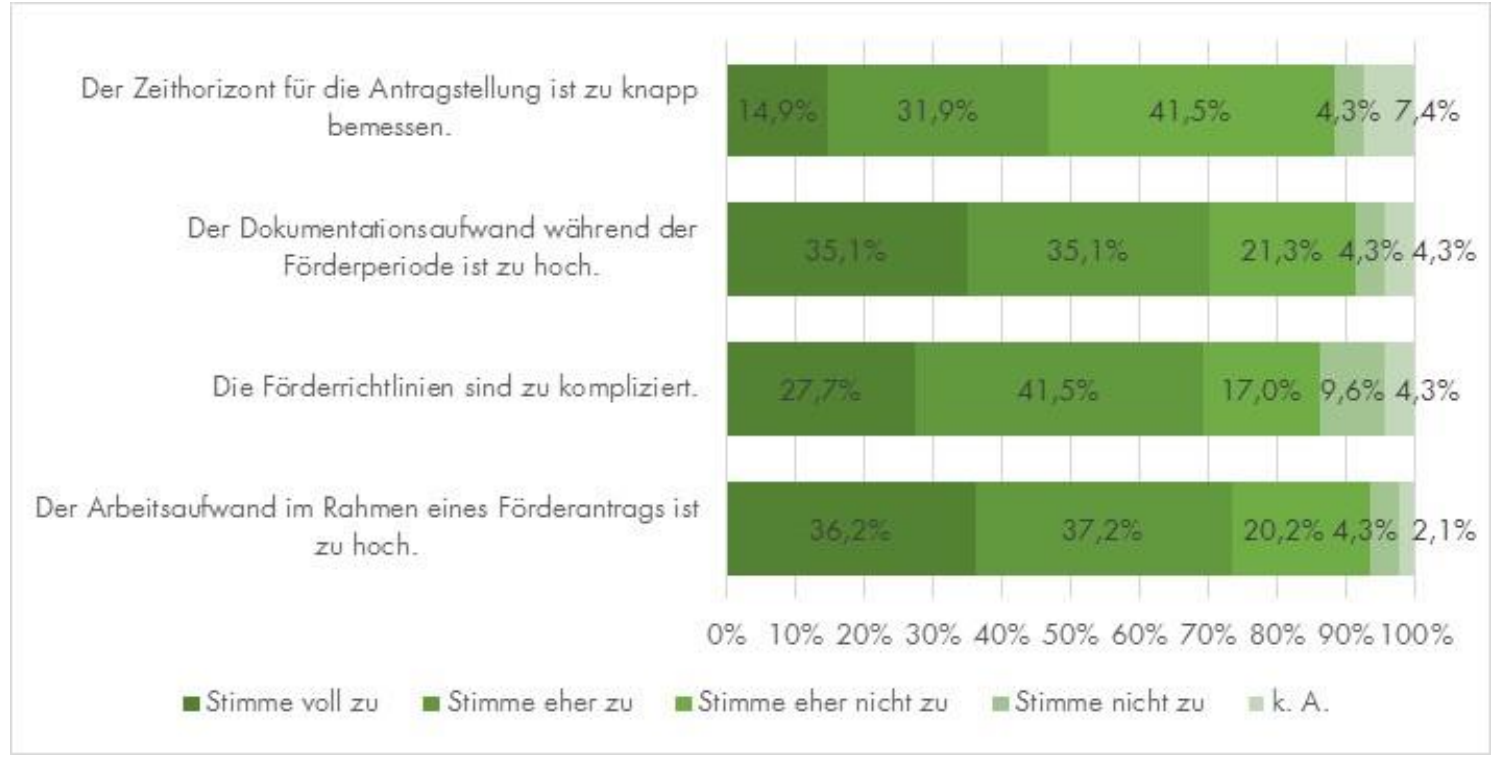

Quelle: Eigene Erhebung ( $\mathrm{n}=94)$, eigene Darstellung.

Zur Untersuchung der These des hohen, zur Beantragung von Fördermitteln notwendigen Arbeitsaufwandes erscheint ebenfalls die nach Einwohnerklassen differenzierte Auswertung der Kommunalbefragung hilfreich (Abbildung 10). An dieser Stelle werden die Unterschiede zwischen größeren und kleineren Kommunen Sachsens deutlich sichtbar. Während die befragten Kommunen der bevölkerungsschwächeren Einwohnerklassen 1 und 2 mit $80 \%$ der These eher bis voll zustimmen (50\% stimmen voll zu), liegt der Anteil der Zustimmung der befragten Kommunen aus der bevölkerungsstarken Einwohnerklasse 5, die insgesamt über größere Verwaltungskapazitäten verfügen können, bei 50,1 \% (lediglich $18,1 \%$ stimmen voll zu). 
Abbildung 10: Befragungsergebnisse zum Arbeitsaufwand nach Einwohnerklassen

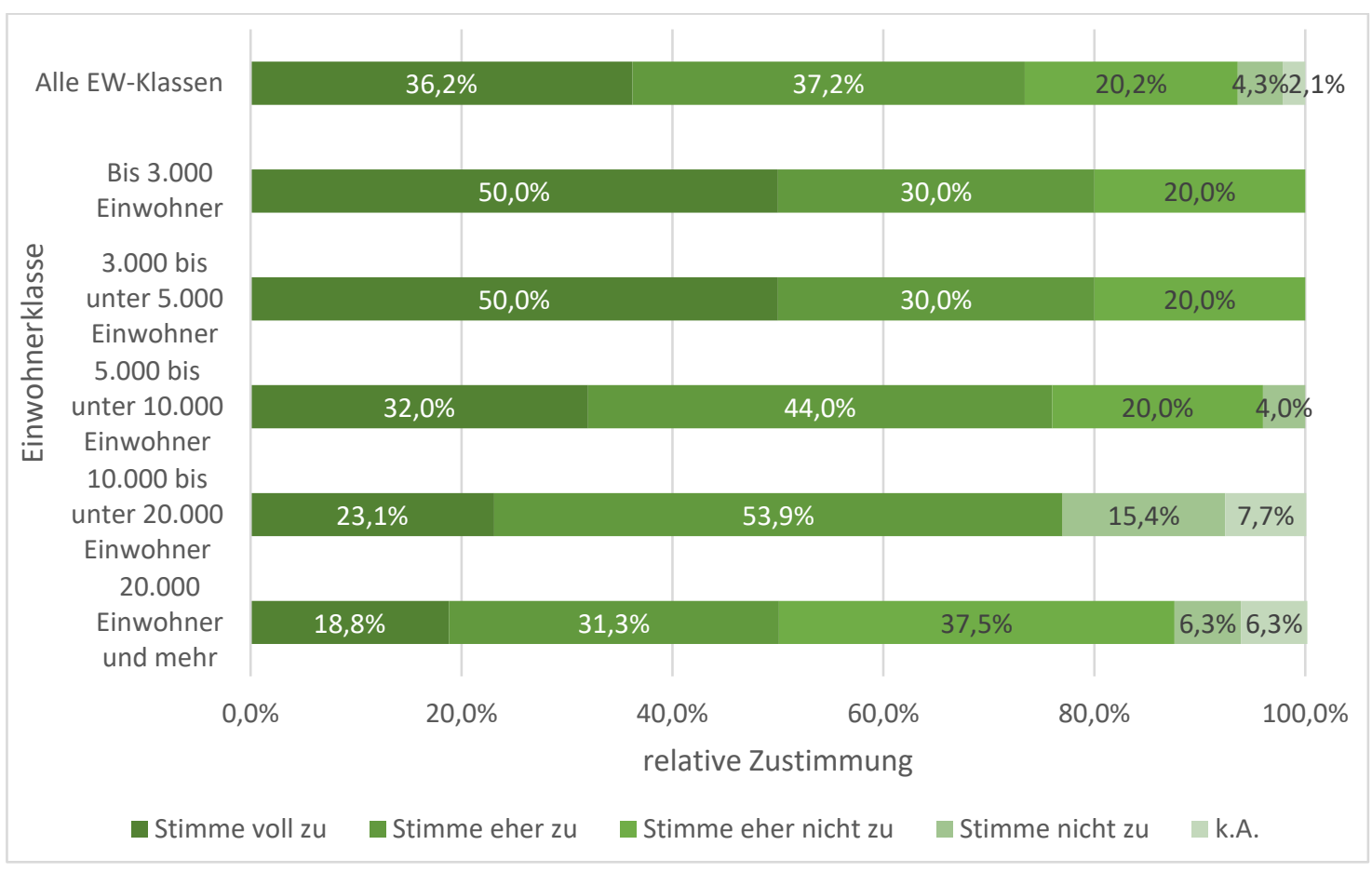

Quelle: Eigene Erhebung ( $\mathrm{n}=94)$, eigene Darstellung.

Ein zusätzliches Hindernis im Rahmen der Fördermittelbeantragung stellen die Fristen für die Einreichung der entsprechenden Anträge dar. Vor dem Hintergrund des hohen Arbeitsaufwandes erhöht sich für die beantragenden, potenziellen Fördermittelempfänger durch diese zumeist recht knapp bemessenen Fristen zusätzlich der Druck. Zudem ist zu bedenken, dass bei Förderprogrammen mit zeitbegrenzten Förderzeiträumen, welche einen zumeist unverzüglichen oder kurzfristigen Einsatz der Fördermittel forcieren, insbesondere der Planungsphase zu Beginn des Förderprozesses häufig weniger Bedeutung beigemessen wird und folglich eine kosteneffiziente Wahrnehmung der Aufgaben durch die Kommunen eine nachgelagerte Rolle spielen könnte. Dennoch bestehen mitunter auch Möglichkeiten, entsprechende Fristen zu verlängern oder sogar Mittel zu übertragen. Dies zeigt das Beispiel einer Umschichtung von 20 Millionen Euro zusätzlicher EU-Mittel im ESF für verschiedene sächsische Fördermittelprogramme für die Region Leipzig. ${ }^{58}$

\footnotetext{
${ }^{58}$ Vgl. Staatsministerium für Wirtschaft, Arbeit und Verkehr des Freistaates Sachsen (2013).
} 


\section{These 7: Zwischen Antragstellung und Fördermittelbescheid vergeht zu viel Zeit. Zudem besteht ein ernstzunehmendes Risiko der Rück- forderung von Fördermitteln.}

Die These, dass zwischen der Beantragung einer Förderung und dem Eingang eines finalen Fördermittelbescheids häufig ein zu langer Zeitraum liegt, wurde im Rahmen der Erhebung der sächsischen Kommunen nicht direkt abgefragt. Dennoch wurde diese These in der Befragung mittels des Freitextfeldes durch viele Kommunen bestätigt. Ein wenig eindeutiges und eher ausgewogenes Ergebnis liefert die Befragung zur These hinsichtlich der Unsicherheit über eine tatsächliche Auszahlung bzw. der Gefahr einer Rückforderung der unter Umständen bereits verwendeten Mittel. Dieser stimmte etwa die Hälfte der befragten Kommunen zu, die andere Hälffe hingegen wies diese zurück.

\section{Abbildung 11: Befragungsergebnisse zu These 7}

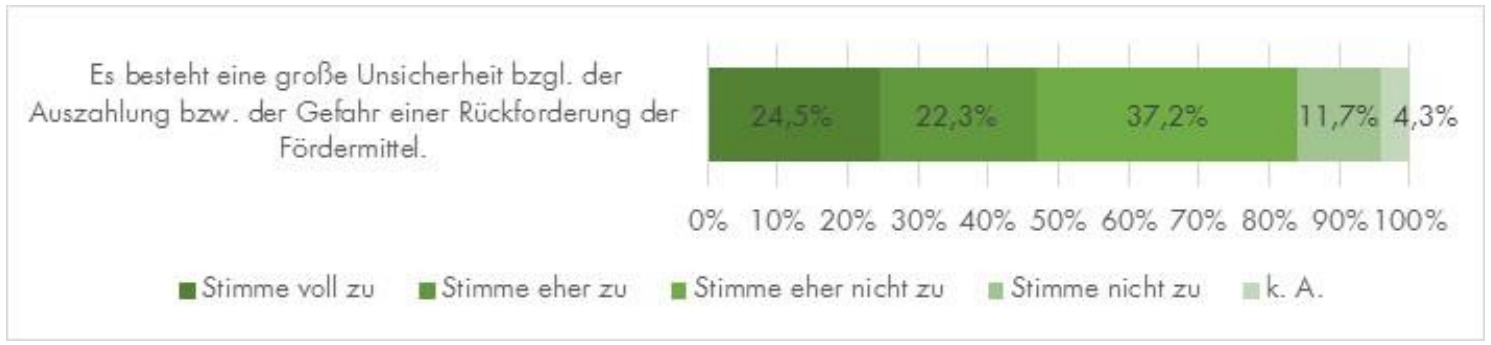

Quelle: Eigene Erhebung ( $\mathrm{n}=94)$, eigene Darstellung.

Als Erklärungsansatz für dieses ungenaue Befragungsergebnis können die je nach Bewilligungsstelle oder Fördermittelprogramm variierenden Regelungen und daraus resultierende Unterschiede in verschiedenen Förderprozessen heran gezogen werden.

\section{These 8: Die Auszahlungsform der Fördermittel ist nicht geeignet.}

In der gängigen Fördermittelpraxis treten die Kommunen zu Beginn bzw. während der Durchführung der zu fördernden Maßnahme in Vorleistung und erhalten die Fördermittel nachgelagert nach der Verwendungsnachweisprüfung. ${ }^{59}$ Das Verfahren der Einzelverwendungsnachweise ist allerdings sehr zeit- und arbeitsaufwendig. Das Befragungsergebnis zur pauschalen Auszahlung als alternative Vergaberegelung zur jetzigen Auszahlungsform unterstreicht diese Einschätzung. Die überwiegende Mehrheit der befragten Kommunen

${ }^{59}$ Siehe auch Abschnitt 1.3. 
würde eine pauschalierte Auszahlung der beantragten Fördermittel $(87 \%)$ im Gegensatz zur derzeitigen Auszahlungsform (13\%) bevorzugen.

Abbildung 12: Würden Sie eine pauschale Auszahlung der Fördermittel der jetzigen Auszahlungsform vorziehen?

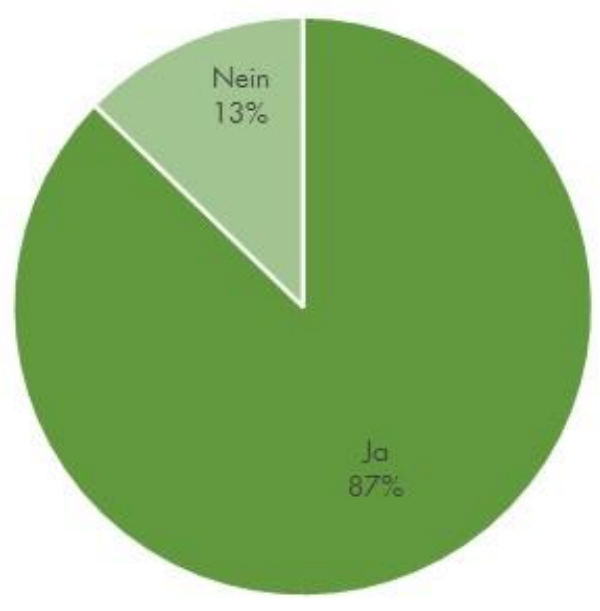

Quelle: Eigene Erhebung ( $\mathrm{n}=94)$, eigene Darstellung.

Zudem stellt für einige Kommunen und insbesondere jene finanziell schwächeren Kommunen, welche die Fördermittel sehr dringend benötigen, die Vorfinanzierung der geplanten Maßnahmen häufig ein Problem dar. Dieses Problem wurde in der Befragung nicht direkt abgefragt, jedoch durch verschiedene Kommunen mehrfach in den Freitextfeldern erwähnt.

\section{These 9: Die Kommunen haben ein quantitatives und qualitatives Perso- nalproblem aufgrund des enormen Aufwands im Rahmen einer Fördermittelbeantragung und -vergabe.}

Sowohl die Bandbreite an verschiedenen kleinteilig geregelten Förderrichtlinien als auch die Fülle an dezentralisiert zur Verfügung gestellten Informationen sowie die zahlreichen Anforderungen und die generelle Komplexität der Fördermittelbeantragung führen zu einem hohen Bedarf an ausreichend geschultem Personal zur Bewältigung dieser Anforderungen. Dieser Bedarf kann in der Praxis oft nur unzureichend und zum Teil überhaupt nicht gedeckt werden. Beispielsweise zeigen die Entwicklungen des Personals in den Bauämtern einen deutlich rückläufigen Trend, welcher zum Personalmangel führt. ${ }^{60}$ Durch die

${ }^{60} \mathrm{Vgl}$. Brand/Steinbrecher (2016), o. S.; Gornig/Michelsen (2017), S. 218. 
bevorstehende Pensionierungswelle droht sogar eine weitere Verschärfung dieses Personalmangels, welchem zumindest kurzfristig nur schwer entgegengewirkt werden kann. ${ }^{61}$ Dieser sinkende Personalbestand bzw. der Mangel an hinreichend qualifiziertem Personal stellt die Kommunen vor dem Hintergrund der steigenden Anforderungen im Rahmen der Fördermittelbeantragung weiterhin vor Herausforderungen. Die Befragungsergebnisse verdeutlichen allerdings eher ein quantitatives, jedoch weniger ein qualitatives Personalproblem der Kommunen. Dies zeigt Abbildung 13. Während fast die Hälfte der befragten Kommunen (44,7\%) der Aussage unzureichender Mitarbeiterressourcen zur Antragstellung von Fördermitteln voll bis eher zustimmte, gaben lediglich $17 \%$ der befragten Kommunen an (voll bis eher zugestimmt), dass das Personal zur Antragstellung nicht ausreichend qualifiziert sei.

\section{Abbildung 13: Befragungsergebnisse zu These 9}

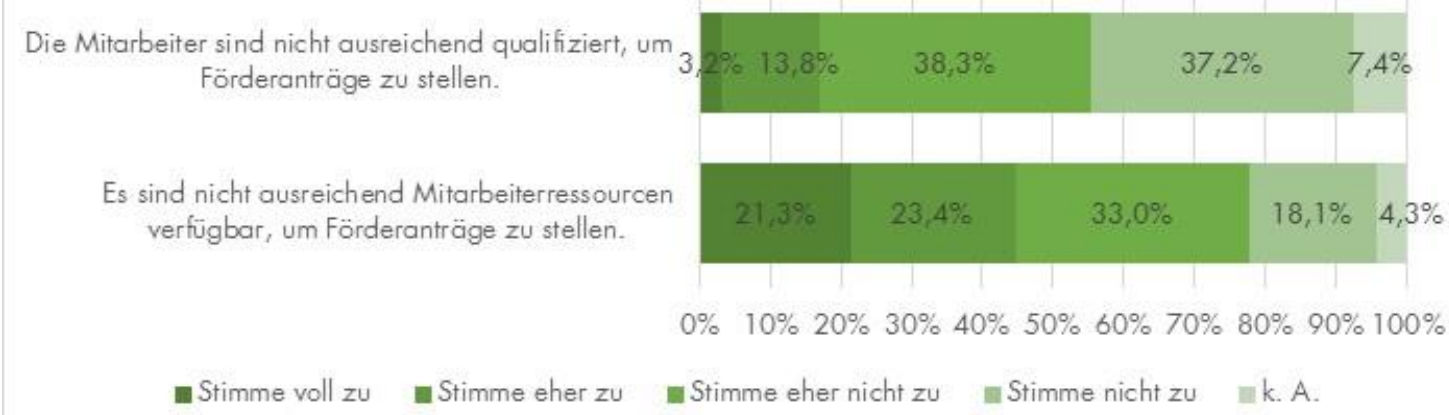

Quelle: Eigene Erhebung ( $\mathrm{n}=94)$, eigene Darstellung.

\section{Handlungsfelder für den Freistaat Sachsen}

Das vorangehende Kapitel hat gezeigt, dass sich die Herausforderungen im Zuge der Förderprozessumsetzung bzw. -abwicklung am stärksten negativ auf den Fördermittelabruf auswirken (vgl. Abschnitt 3.3). Ein wesentliches Handlungsfeld, um den Fördermittelabruf zu verbessern, besteht folglich darin, den Förderprozess zu vereinfachen und die damit verbundenen Transaktionskosten in der Verwaltung zu senken. Die Ausgestaltung der Förderprogramme stellt ebenfalls einen wesentlichen Einflussfaktor dar (vgl. Abschnitt 3.2). Hier birgt insbesondere die Verstetigung von Förderprogrammen Verbesserungspotenzial

${ }^{61}$ Vgl. Institut der deutschen Wirtschaft Köln e.V. (2016), o. S. 
hinsichtlich des kontinuierlichen Mittelabrufs. Informations- und Zuständigkeitsprobleme spielen dagegen offenbar eine nachgeordnete Rolle: Diese tragen zwar nicht zu einer Erleichterung des Förderprozesses bei, sie verhindern die Fördermittelbeantragung aber auch nicht (vgl. Abschnitt 3.1). Ein ähnliches Bild ergab sich auch im Rahmen der Dialogveranstaltung mit allen am Förderprozess beteiligten Akteuren: Bei der abschließenden Gewichtung der zuvor diskutierten Handlungsfelder wurden durch die Kommunalvertreter vorrangig Schlagworte wie Vereinfachung, Bürokratieabbau und Pauschalierung genannt. Im Folgenden werden nochmals ausgewählte Handlungsfelder diskutiert. Dabei sollen möglichst konkrete und vom Freistaat Sachsen beeinflussbare Handlungsfelder mit Blick auf antragsgebundene Fachförderprogramme, d.h. innerhalb des bestehenden Systems benannt werden. Sowohl Schwierigkeiten bezüglich EU-Richtlinien als auch grundsätzlichere Fragestellungen zur angemessenen Finanzausstattung der Kommunen würden im Rahmen dieser Analyse zu weit führen und werden deshalb nicht tiefergehend thematisiert, wenngleich gerade diese systemischen Aspekte häufig im Fokus der Kritik stehen.

\subsection{Einheitliche Datenbank}

Zunächst erscheint eine einheitliche Fördermitteldatenbank sehr sinnvoll zur Unterstützung der kommunalen Ebene bei der Suche nach geeigneten Förderprogrammen bzw. für einen generellen Überblick über die Fördermöglichkeiten und die Fördermittellandschaft in Deutschland. Die Erstellung einer solchen einheitlichen Fördermitteldatenbank erfordert mindestens die Verknüpfung oder sogar die Konsolidierung der bisher bestehenden Förderdatenbanken des Bundes und der Länder (bspw. Förderdatenbank des Bundesministerium für Wirtschaft und Energie, Datenbank des Freistaats Sachsen (FÖMISAX), Daten der $\mathrm{SAB}$ ). Im Rahmen der Erstellung dieser Datenbank müssten sowohl die Datenstruktur angepasst als auch die Redundanzen beseitigt und widersprüchliche Informationen aktualisiert werden. An dieser Stelle ist allerdings das Problem der Umsetzung einer solchen Datenbank anzumerken. Während in der Förderdatenbank des Bundesministeriums für Wirtschaft und Energie ausschließlich Bundesprogramme aufgeführt sind, verfügen die FÖMISAX-Datenbank und auch die Informationsseiten der SAB lediglich über Landes- und ESFProgramme, nicht jedoch über jene Bundesprogramme, welche bspw. ebenfalls die kommunale Ebene Sachsen adressieren. Eine einheitliche Fördermitteldatenbank müsste dem- 
entsprechend im Idealfall sämtliche Bundes- und Landesprogramme abbilden und auf Bundesebene angesiedelt sein. Eine Alternative wäre eine sächsische Förderdatenbank, welche alle für die sächsische Kommunalebene möglichen Förderprogramme des Bundes und des Freistaates Sachsen sowie die ESF-Programme vereint. Allerdings sind derzeit weder der Bund noch die Länder oder die entsprechenden Landesförderbanken bestrebt, eine solche einheitliche Datenbank zu erstellen.

\subsection{Einheitliche Ansprechpartner}

Zur Bündelung von Zuständigkeiten und Informationen sowie zur Steigerung der Übersichtlichkeit kann eine zentrale Anlaufstelle bzw. Fördermittelausgabe für Anträge, Fragen und Bewilligungen dienen. Die entsprechenden Fachministerien müssten grundsätzlich zuständig bleiben. Allerdings würde der Beantragungs-, Bewilligungs- und Vergabeprozess für die verschiedenen Förderprogramme in dieser zentralen Anlaufstelle gebündelt und die Kommunikation mit den Kommunen auf diese beschränkt werden. So stünden die zentrale Fördermittelausgabe und die zuständigen Fachministerien in einem direkten und regelmäBigen Austausch zur Optimierung der Prozesse. Zusätzlich wäre für eine Vereinfachung der Fördermittelvergabe ebenfalls eine Verbesserung der Absprache zwischen den Fachministerien hilfreich. Für die Kommunen würde diese Umstrukturierung eine enorme Erleichterung in der Beantragung von Fördermitteln und im Bewilligungsverfahren darstellen. In diesem Zusammenhang erscheint ebenfalls eine einheitliche Formblattstruktur bzw. ein einheitliches Dokumentenmanagement sinnvoll (siehe folgendes Handlungsfeld "Standardisierung / Digitalisierung").

\subsection{Standardisierung / Digitalisierung}

Grundsätzlich dienen zur Schaffung einer Einheitlichkeit und Übersichtlichkeit in der Fördermittelbeantragung und -vergabe ein gleicher Aufbau der Beantragungsformulare und eine einheitliche Dokumentstruktur über verschiedene Förderrichtlinien hinweg. Dadurch könnten ebenfalls bereits ausgefüllte Formulare für zukünftige Anträge wiederverwendet werden. Zur zusätzlichen Optimierung dieser wiederkehrenden Prozesse stellt darüber hinaus eine Online-Plattform einen möglichen Lösungsansatz dar. Diese Plattform könnte ei- 
nerseits dazu dienen, jene Dokumente hochzuladen, zentral abzuspeichern, künftig mehrfach abzurufen und wiederzuverwenden. Anderseits wären ebenfalls die zentrale Beantragung der Fördermittel durch die Kommunen sowie die Möglichkeit einer Statusabfrage und die Versendung der Bewilligungsbescheide durch die zentrale Vergabestelle an die einzelnen Kommunen mithilfe einer solchen Online-Platfform denkbar. Diese Maßnahmen würden zudem einen wesentlichen Beitrag zum Bürokratieabbau leisten, indem sie wiederkehrende Prozesse beschleunigen und Schnittstellenprobleme mindern. Im Rahmen der Dialogveranstaltung wurde der Bürokratieabbau mehrfach als Anforderung an die zu überarbeitende Fördermittelvergabe genannt.

Hinsichtlich der bürokratischen Anforderungen bzw. Hürden innerhalb eines Fördermittelbeantragungs- und -vergabeprozesses könnte künftig zusätzlich nach der Höhe des Fördervolumens differenziert werden. Während bei Förderanträgen mit verhältnismäßig hohen Fördervolumina ein spezifisches Antragsverfahren zweckmäßig erscheint, wären hingegen bei Förderanträgen mit relativ geringen Volumina vereinfachte Förderanträge denkbar. Entsprechende Grenzen müssten nachgelagert festgelegt werden.

\subsection{Fachliche Unterstützung der Kommunen}

Im Rahmen der Untersuchung der Herausforderungen bei der Förderung kommunaler Infrastrukturprojekte ergab sich ein weiteres Handlungsfeld zur Unterstützung der Kommunen bei der Fördermittelbeantragung und -vergabe hinsichtlich häufig bestehender quantitativer und qualitativer Personalprobleme. Diese wurden in Kapitel 3 unter der These 9 bereits erläutert. Zum Abbau dieses Problems besteht in engem Zusammenhang zu Handlungsfeld 2 die Möglichkeit der Einrichtung einer zentralen Anlauf- und Beratungsstelle für tiefergehende Fachfragen zur Fördermittelbeantragung und -vergabe seitens der Kommunen. Eine solche Beratungsgesellschaft könnte innerhalb einer in Handlungsfeld 2 beschriebenen, zu errichtenden, einheitlichen Anlaufstelle für Kommunen implementiert werden. Darüber hinaus können ebenfalls interkommunale Kooperationen zur Lösung jener Personalprobleme dienen. 


\subsection{Umstrukturierung und Reduzierung der Anzahl an Förder- mittelprogrammen}

Ein weiteres, besonders notwendiges Handlungsfeld stellt die Umstrukturierung der Fördermittellandschaft dar. Neben der großen Bandbreite an Förderprogrammen tragen zusätzlich die häufig sehr spezifischen und kleinteiligen Regelungen der Vergabe der entsprechenden Fördermittel zur Unübersichtlichkeit bei. Durch eine wesentliche Modifizierung, Konsolidierung und teilweise sogar Reduzierung von Förderrichtlinien kann ein besserer Überblick über die Fördermöglichkeiten geschaffen werden. Dadurch wird ebenfalls eine einfachere Antragstellung sowie Mittelverteilung ermöglicht. Gleichzeitig ist damit nicht die Kürzung des gesamthaften Fördermittelvolumens gemeint. Vielmehr wird zum Zweck eines besseren Überblicks sowohl für Antragsteller als auch die Bewilligungsstellen auf eine übersichtliche Anzahl an größeren, aus gegenwärtig verschiedenen Programmen konsolidierten Förderrichtlinien abgestellt.

Im Allgemeinen muss berücksichtigt werden, dass der originäre Zweck von Fördermittelprogrammen weniger darin besteht, der kommunalen Ebene daverhaft finanzielle Unterstützung zu leisten, sondern vielmehr darin, politische Akzente und finanzielle Impulse zu setzen. Derzeit ist die finanzielle Situation der Kommunen allerdings dadurch charakterisiert, dass aufgrund ihrer begrenzten originären Finanzausstattung (Allgemeine Deckungsmittel) stark auf die zum Teil sehr langfristig zur Verfügung stehenden Fördermittel angewiesen sind. ${ }^{62}$ Die Mittel der Kommunen reichen häufig nicht aus, um die öffentlichen Aufgaben einschließlich einer bedarfsgerechten Infrastrukturausstattung vollumfänglich bereitzustellen. Zur punktuellen, finanziellen Unterstützung der Kommunen bei ihren Infrastrukturmaßnahmen dienen deshalb häufig die politisch intendierten Fördermittelprogramme, welche allerdings der kommunalen Selbstverwaltung entgegenwirken. Demzufolge zielt dieses Handlungsfeld nicht nur auf die Umstrukturierung und Reduzierung der Anzahl an Fördermittelprogrammen ab, sondern auch generell auf die Erhöhung der finanziellen Grundausstattung der kommunalen Ebene. Mit höheren Schlüsselzuweisungen wären die Kommunen in ihrer finanziellen Handlungsfähigkeit nicht mehr in solch starkem Maße abhängig von der Fördermittelvergabe. Die Frage hinsichtlich einer Aufstockung

62 Die Allgemeinen Deckungsmittel (Steuern und allgemeine Zuweisungen) decken im Durchschnitt nur rund $50 \%$ der Gesamtausgaben. Vgl. Lenk/Hesse/Kratzmann (2017), S. 61-65. 
der finanziellen Grundausstattung der Kommunen und der gleichzeitigen Senkung von Fördermitteln stellt allerdings eine Diskrepanz zwischen der Landes- und der Kommunalpolitik dar. Während die Landespolitik die Absicht verfolgt, die kommunalen Aktivitäten und Investitionen über die Fördermittelprogramme zu steuern, hat die Kommunalpolitik den Anspruch, über die finanziellen Handlungen der kommunalen Ebene gemäß dem Postulat der kommunalen Selbstverwaltung selbst, entsprechend dem dringendsten Bedarf, zu entscheiden. An dieser Stelle bleibt ebenfalls zu berücksichtigen, dass die sächsischen Fördermittel über einen Zeitraum von mehreren Jahren nicht vollständig abgerufen wurden (vgl. Abbildung 2). Zwischen 2010 und 2015 sind die verfügbaren Mittel stetig gesunken. Der Anteil der verbleibenden Restmittel an den verfügbaren Fördermitteln blieb in dem Zeitraum annähernd konstant. Folglich führt die jährliche Übertragung der Restmittel in die Folgejahre zu einer Senkung der zur Verfügung stehenden Mittel im Zeitverlauf. Diese Entwicklung zeigt ebenfalls, dass eine Umstrukturierung der Fördermittelprogramme insbesondere vor dem Hintergrund der zunehmend angespannten Finanzlage vieler (sächsischer) Kommunen notwendig erscheint.

\subsection{Erweiterung der Fördergegenstände}

In einem engen Zusammenhang zu dem vorhergehenden Handlungsfeld der Umstrukturierung der Fördermittelprogramme steht die Erweiterung der Fördergegenstände. Hiermit ist insbesondere der überholte Fokus auf "klassische" Investitionen und die nachrangige Berücksichtigung von Instandhaltungsmaßnahmen gemeint. Aufgrund der Umstellung der kommunalen Rechnungslegung von der Kameralistik zur doppischen Buchführung werden Investitionen und Erhaltungsaufwendungen in die kommunale Infrastruktur konsequenter voneinander abgegrenzt als in der kameralen Vergangenheit. Demzufolge sollten nicht nur die "klassischen" Investitionen, sondern insbesondere die Erhaltungsaufwendungen künftig im Rahmen der Ausgestaltung von Förderrichtlinien in stärkerem Maße berücksichtigt werden. Im Rahmen der These 4 wurde bereits auf die Schwierigkeit hingewiesen, dass bei Instandhaltungsmaßnahmen häufig die Bagatellgrenze unterschritten wird und infolgedessen Fördervolumen und Kosten der Prozessabwicklung in einem ungünstigen Verhältnis stehen (vgl. Abschnitt 3.2). In Kombination mit dem Handlungsfeld Standardisierung / Digitalisierung können die Verfahren aber ggf. so vereinfacht werden, dass auch niedrige Fördervolumina in einem angemessenen Verhältnis zum Abwicklungsaufwand 
stehen. Darüber hinaus wäre auch die verstärkte Förderung von Planungsleistungen sinnvoll.

\section{7 Überarbeitung der Rechtsgrundlagen}

Zur Vereinfachung der Fördermittelbeantragung und -vergabe könnte weiterhin eine starke Überarbeitung der entsprechenden Rechtsgrundlagen dienen. In diesem Zusammenhang erscheint beispielsweise eine Isolierung der Förderrichtlinien von der Sächsischen Haushaltsordnung (SäHO) bzw. mindestens eine Überarbeitung und Vereinfachung der Verwaltungsvorschrift zu § $44 \mathrm{SäHO}(\mathrm{VwV}$ zu § $44 \mathrm{SäHO}$ ) sinnvoll. Im Rahmen der Dialogveranstaltung wurde dies ebenfalls vermehrt geäußert. Zusätzlich wurde in dem Austausch zwischen Vertretern von Kommunen und Spitzenverbänden, Landesministerien und -ämtern, der Sächsischen Aufbaubank und des Sächsischen Rechnungshofes eine starke Kritik an der derzeitigen Verwaltungsvorschrift zu $\S 44$ SäHO deutlich. Diese sei entsprechend aufgebläht, da durch den Gesetzgeber in der Vergangenheit wiederholt Anpassungen und insbesondere Ergänzungen vorgenommen wurden, sobald etwaige Regelungslücken oder außerplanmäßige Förderungsverläufe bei Projekten bekannt wurden. Aufgrund des sich daraus ergebenden verhältnismäßig großen Umfangs an spezifischen Regelungen wird eine zielgerichtete Förderung durch diese Rechtsgrundlage in zunehmendem Maß eingeschränkt.

Zusätzlich wurde im Rahmen der Dialogveranstaltung mehrfach der Bedarf nach einer angemessenen Fehlerquote deutlich. Diese spiegelt jenen Anteil an den insgesamt eingesetzten Fördermitteln wider, welcher nicht unter vollumfassender Einhaltung sämtlicher Rechtsgrundlagen und -vorschriften vergeben wurde. Dies erhöht die Planungssicherheit für Kommunen, die bereits erfolgreich Fördermittel beantragt haben und sich in der Auszahlungs- und Prüfphase befinden. Das verminderte Risiko von Rückforderungen bei leichteren (zumindest nicht vorsätzlichen oder grob fahrlässigen) Verstößen gegen die Förderrichtlinien könnte den Mittelabfluss trotz angespannter kommunaler Verwaltungskapazitäten beschleunigen.

Im Sinne einer stärkeren Pauschalisierung der Mittelvergabe (s. Handlungsfeld 4.10) erscheint eine flexiblere Verwendung von kleineren Förderbeträgen unterhalb einer gesetz- 
lich festgelegten Bagatellgrenze sinnvoll. Für solche kleineren Förderprojekte wären ebenfalls geringere bürokratische Anforderungen hinsichtlich der Fördermittelbeantragung und -vergabe vorteilhaft. Einen weiteren Impuls, welcher innerhalb der im vergangenen Jahr durchgeführten Dialogveranstaltung entstand, stellt die Angleichung des Investitionsbegriffs im Haushalts- und Förderrecht dar. Diese beiden Rechtsgrundlagen stellen auf unterschiedliche Auffassungen über Investitionen auf der kommunalen Ebene und der Landesebene ab.

\subsection{Steigerung der Transparenz}

Grundsätzlich sollte im Rahmen der Vergabe von öffentlichen Fördermitteln mehr Transparenz geschaffen und kontinuierlich beibehalten werden. Dazu könnte eine jährliche Berichterstattung dienen. In dieser sollten die durch den Haushalt zur Verfügung gestellten, die beantragten sowie die bewilligten bzw. abgerufenen Fördermittel in einem Haushaltsjahr fachressortübergreifend aufgestellt werden. Daneben könnten in diesem Jahresbericht auch die Anzahl der gestellten Förderanträge sowie die Höhe der verbliebenen oder in andere Programme übertragenen Restmittel veröffentlicht werden. Einen wesentlichen Bestandteil des Jahresberichtes sollten die Abrufquoten einnehmen.

Hinsichtlich der in Kapitel 2 beschriebenen Schwierigkeiten in der Ermittlung von Abrufquoten, insbesondere aufgrund des kontinuierlichen Aufstauens von Fördermitteln, sollten entsprechende Lösungsansätze gefunden werden, jene Quoten mit geeigneten Methoden zu erheben und darzustellen. Ein Lösungsansatz besteht darin, im Rahmen der Ermittlung einer Abrufquote ausschließlich die zu Beginn einer Förderperiode in der entsprechenden Förderrichtlinie zur Verfügung stehenden Mittel zu betrachten. Die Abrufquote würde dann das Verhältnis aus den in der Förderperiode bewilligten Mitteln und den ursprünglich zur Verfügung gestandenen Mitteln bilden. Die zusätzlichen Mittel aus Übertragungen oder ausgelaufenen Richtlinien, welche unter Umständen aus anderen Förderprorammen im Zeitverlauf der Förderperiode in jene Förderrichtlinien eingehen, würden in diesen Abrufquoten nicht betrachtet werden. Dadurch finden nur die ursprünglich, durch den Haushalt geplanten Mittel Eingang in diese Betrachtung. Eine weitere Maßnahme zur konsequenteren Trennung zwischen ursprünglich geplanten Fördermitteln und übertragenen Restmitteln wäre die Einrichtung eines neuen Fördertopfes "Restmittel". Die zu übertragenden Restmit- 
tel würden dementsprechend als Zusatzmittel in diesem neuen Fördertopf "Restmittel" verbucht werden und könnten daraufhin für Fördermaßnahmen gemäß dem höchsten Bedarf an die Kommunen vergeben werden. Dazu müssten zuvor allerdings die entsprechenden Bedarfe der Kommunen definiert und mithilfe einer geeigneten Methodik in eine Rangfolge gesetz† werden. Andernfalls sollte nach alternativen Lösungen gesucht werden, wie mit jenen Restbeträgen verfahren wird.

\subsection{Verlässlichkeit / Verstetigung der Mittelvergabe}

Aus kommunaler Sicht ist das bestehende System der Fördermittelvergabe gegenwärtig dadurch charakterisiert, dass aus einer erfolgreichen Beantragung von Fördermitteln nicht zwangsläufig eine Bewilligung jener Mittel folgt. Sowohl die Vergabe als auch die Höhe der Fördermittel ist ungewiss. Zur sicheren und effektiven Planung und Durchführung kommunaler Infrastrukturmaßnahmen erscheint es hilfreich, die Vergabe von Fördermitteln in einem stärkeren Maße zu verstetigen. Dementsprechend müssten bestehende Fördertöpfe erweitert bzw. aufgestockt werden, sofern die Summe der beantragten Fördermittel den Betrag der zur Verfügung stehenden Fördermittel in einer Förderperiode übersteigt und der Fördertopf somit vorfristig ausgeschöpft wäre. Ebenfalls erscheint in diesem Fall sinnvoll, entsprechende Förderprogramme nachzulegen, bis alle loder zumindest ein großer Teil der) Antragsteller bedient sind. Daneben wäre auch eine Verlängerung des Zeithorizonts des Förderprogrammes, bspw. des Bewilligungszeitraums oder der Abruffristen denkbar. Durch diese Maßnahmen könnte verstärkt eine Verlässlichkeit der Fördermittelvergabe geschaffen werden, welche aus Sicht der Kommunen insbesondere vor dem Hintergrund der häufig angespannten und volatilen Finanzlage notwendig erscheint. Ein weiterer Vorteil, den diese Maßnahmen bieten würden, stellt die Reduzierung der häufig im Zusammenhang mit der Fördermittelvergabe auftretenden, vielfach stark kritisierten Mitnahmeeffekte dar. Entsprechend könnte eine Vergabe von Fördermitteln gemäß dem höchsten Bedarf anstatt gemäß der höchsten Wahrscheinlichkeit einer Mittelvergabe erreicht werden. Zur Realisierung dieser Effekte und Schaffung einer Programmkontinuität müssten die Fördermittelprogramme durch das Land langfristiger geplant und aufgelegt werden. Die Erhebung, Analyse und Auswertung der kommunalen Investitionsbedarfe für einen mehrjährig in die Zukunft reichenden Zeithorizont können zu einer langfristigen Planung von Fördermittelprogrammen wesentlich beitragen. 
Dennoch bleibt zu berücksichtigen, dass eine Programmkontinuität und Verstetigung der Fördermittelvergabe der in Handlungsfeld 5 angestrebten Senkung des Einflusses politisch intendierter Fördermittelprogramme und Erhöhung der grundlegenden kommunalen Finanzausstattung zum Ziel der Sicherung der kommunalen Selbstverwaltung der Kommunen zum Teil entgegensteht. Aus diesem Grund sollte die Mittelvergabe auf der Zeitachse in Form von längerfristig bestehenden bzw. wiederkehrenden größeren Förderprogrammen verstetigt werden. Kleinere, zeitlich limitierte Förderprogramme, welche ausschließlich für stark eingegrenzte Förderbereiche vorbehalten sind und einer vielfältigen Mittelverwendung entgegenstehen, sollten hingegen nach Möglichkeit reduziert werden.

\subsection{Pauschalisierung / Flexibilisierung}

Als generelles Handlungsfeld ist zusätzlich eine stärkere Flexibilisierung in der Fördermittelvergabe zu nennen. Eine Pauschalisierung bzw. eine flexiblere Vergabe von Fördermitteln ermöglicht ein breiteres Spektrum an Verwendungsmöglichkeiten der Fördermittel für die Kommunen (sog. Investitionspauschale). Hingegen führt eine Fördermittelvergabe im Rahmen von zahlreichen kleinteiligen, stark eingegrenzten Förderprogrammen zu einer Verengung entsprechender Einsatzmöglichkeiten. Demzufolge erscheint eine Fördermittelvergabe entsprechend dem Budgetgedanken aus Sicht der Kommunen deutlich vorteilhafter als eine Fördermittelvergabe im Sinne der Sächsischen Haushaltsordnung, welche auf den Ausnahmetatbestand abstellt.

In diesem Zusammenhang entsteht allerdings ein Zielkonflikt. Einerseits sollte das Ziel verfolgt werden, die Mittelvergabe künftig flexibler und stärker pauschaliert zu gestalten. Andererseits wird im Rahmen der Vergabe der Fördermittel auch künftig der Wunsch nach Umsetzung von Einzelfallgerechtigkeit bestehen. Dazu kann eine entsprechende Dokumentation und Erläuterung der Mittelvergabe sowie der Mittelverwendung durch die Kommunen dienen. Auch Mittel, die der Kommune auf pauschalem Wege zugehen, können und sollen zur Deckung hochspezifischer Infrastrukturbedarfe eingesetzł werden. 


\section{Zusammenfassung und Ausblick}

In der vorliegenden KOMKIS Analyse wurde zunächst der Fördermittelbegriff aus rechtlicher und finanzwissenschaftlicher Perspektive geklärt, ein Überblick über die Fördermittellandschaft des Freistaates Sachsen dargestellt sowie ein beispielhafter Förderprozess von der Beantragung bis hin zur Vergabe und Auszahlung der entsprechenden Fördermittel skizziert. Über die daran anknüpfende Erläuterung der Diskrepanz zwischen den zur Verfügung stehenden und den tatsächlich abgerufenen Fördermitteln hinaus wurden die drei wesentlichen Herausforderungen im Rahmen der Fördermittelvergabepraxis bei kommunalen Infrastrukturprojekten charakterisiert. Diese bestehen in

1. dem hohen Informationsaufwand und der mangelnden Übersicht über die zahlreichen Zuständigkeiten

2. der generellen Ausgestaltung der Fördermittelprogramme und

3. der Umsetzung bzw. dem Vollzug des gesamten Fördervergabeprozesses.

Innerhalb dieser drei identifizierten Herausforderungen wurden die im Vorhinein aufgestellten Thesen mit den genannten Ergebnissen überprüft. Im weiteren Schritt wurden insgesamt zehn Handlungsfelder zur Vereinfachung der Fördermittelvergabe am Beispiel des Freistaates Sachsen erarbeitet und diskutiert. Diese werden im Folgenden nochmals kurz anhand der aufgestellten Thesen zusammengefasst:

Informations- und Zuständigkeitsprobleme:

These 1: Der Informationsaufwand, um ein geeignetes Förderprogramm zu finden, ist zu hoch.

These 2: Zahlreiche Ansprechpartner und je nach Förderprogramm variierende Bewilligungsstellen erschweren die Übersicht.

Zur Lösung der Informations- und Zuständigkeitsprobleme könnten sowohl eine einheitliche Fördermitteldatenbank als auch einheitliche Ansprechpartner zur fachlichen Unterstützung der Kommunen sowie eine umfangreichere Digitalisierung und Standardisierung der Fördermittelvergabe dienen. 
Ausgestaltung der Fördermittelprogramme:

These 3: Die Förderprogramme sind nicht bedarfsgerecht.

These 4: Es werden primär investive Maßnahmen, aber kaum Instandhaltungsmaßnahmen gefördert.

These 5: Die Förderquote ist zu gering bzw. der Eigenanteil ist zu hoch.

Durch die Umstrukturierung bzw. Reduzierung der Anzahl an Fördermittelprogrammen und eine Erweiterung der Fördergegenstände über die "klassischen" Investitionen hinaus auf Erhaltungsmaßnahmen könnte die Ausgestaltung der Förderprogramme zum Ziel einer effizienteren und flexibleren Mittelverwendung der kommunalen Ebene verbessert werden.

\section{Förderprozessumsetzung/-abwicklung:}

These 6: Der Arbeits- und Dokumentationsaufwand im Rahmen eines Förderantrags ist zu hoch. Außerdem sind die Beantragungs- bzw. Abruffristen zu knapp bemessen.

These 7: Zwischen Antragstellung und Fördermittelbescheid vergeht zu viel Zeit. Zudem besteht ein ernstzunehmendes Risiko der Rückforderung von Fördermitteln.

These 8: Die Auszahlungsform der Fördermittel ist nicht geeignet.

These 9: Die Kommunen haben ein quantitatives und qualitatives Personalproblem aufgrund des enormen Aufwands im Rahmen einer Fördermittelbeantragung und -vergabe.

Zur Bewältigung der gegenwärtig bestehenden Herausforderungen im Rahmen der Umsetzung eines Fördermittelvergabeprozesses erscheint bspw. die Überarbeitung der Rechtsgrundlagen sinnvoll. Darüber hinaus sollte die Steigerung der Transparenz mithilfe einer regelmäßigen Berichterstattung über die periodenweise zur Verfügung stehenden Fördermittel in stärkerem Maß forciert werden. Grundsätzlich stellt eine Verstetigung der Mittelvergabe auf der Zeitachse durch die Erweiterung oder Aufstockung von Fördertöpfen und insbesondere durch längerfristig bestehende bzw. wiederkehrende, größere Förderprogramme, dessen Mittel flexibler eingesetzł werden können, ein notwendiges Handlungsfeld dar. Kleinere, zeitlich limitierte Förderprogramme für stark eingegrenzte Förderbereiche sowie der Arbeits- und Dokumentationsaufwand im Rahmen der Fördermittelbeantragung und -vergabe sollten hingegen reduziert werden. Letzterer könnte beispiels- 
weise durch die erläuterte, zunehmende Digitalisierung und Standardisierung der Fördermittelvergabe gesenkt werden. Vor dem Hintergrund der zum Teil stark begrenzten Finanzausstattung vieler Kommunen und der daraus resultierenden, zunehmenden Abhängigkeit von Fördermitteln erscheint eine stärkere Flexibilisierung in der Fördermittelvergabe notwendig. Diese könnte durch die Verstetigung der Mittelvergabe und durch die Umstrukturierung der Fördermittelprogramme realisiert werden. Da durch die politisch intendierten Förderprogramme allerdings Förderschwerpunkte gesetz† werden und somit der kommunalen Selbstverwaltung entgegengewirkt wird, stellt ebenfalls die generelle Erhöhung der finanziellen Grundausstattung der Kommunen lggf. zulasten antragsgebundener Programme) ein denkbares Handlungsfeld dar. 


\section{Literatur}

Aulbert, Imke (2010): Staatliche Zuwendungen an Kommunen, 1. Aufl., Baden-Baden.

Brand, Stephan / Steinbrecher, Johannes (2016): Erst mehr Geld und jetzł mehr Personal - was benötigen Kommunen für Investitionen? in: KfW Research, Fokus Volkswirtschaft, Nr. 151, Frankfurt am Main.

Bundesministerium für Wirtschaft und Energie (2017): Förderdatenbank zu Förderprogrammen und Finanzhilfen des Bundes, der Länder und der EU, online abrufbar unter:

http://www.foerderdatenbank.de/, zuletzt aufgerufen am 19.10.2017.

Deutscher Städte- und Gemeindebund (2017): Bundesfördermittel - Rufen Kommunen die Gelder ab?, in: Kommunal. Wir Gestalten Deutschland., online abrufbar unter https://kommunal.de/artikel/bundesfoerdermittel-kommunen/, zuletzt aufgerufen am 22.05.2018.

Drebes, Jan/ Quadbeck, Eva (2016): Kommunen investieren zu langsam, in: RP Online vom 9. September 2016, online abrufbar unter:

http://www.rp-online.de/politik/deutschland/hilfe-fuer-leere-kassen-kommunen-investieren-zulangsam-aid-1.6247176, zuletzt aufgerufen am 05.12.2017.

Europäische Kommission (2018): EU-Förderung in Deutschland, online abrufbar unter https://ec.europa.eu/germany/eu-funding/grants_de, zuletzł aufgerufen am 03.09.2018.

Frankfurter Allgemeine Sonntagszeitung (2017): Viel Geld, kaum Projekte, Der Bund stellt Milliarden Euro zur Verfügung, wird sie aber oft nicht los, 05.11.2017, online abrufbar unter: http://www.genios.de/presse-archiv/artikel/FAS/20171 105/viel-geld-kaum-projekte-der-bundst/SD1201711055275146.html, zuletzt aufgerufen am 17.05.2018.

Freistaat Sachsen (2016): Sächsisches Förderprofil 2015/2016 zum Sächsischen Staatshaushaltsplan, online abrufbar unter: https://www.finanzen.sachsen.de/download/Foerderprofil_2015_2016.pdf, zuletzt aufgerufen am 17.01.2018.

Freistaat Sachsen (2018): Sächsisches Förderprofil 2017/2018 zum Sächsischen Staatshaushaltsplan, online abrufbar unter: https://www.finanzen.sachsen.de/download/foerderprofil.pdf, zuletzt aufgerufen am 17.04.2018.

Gornig, Martin / Michelsen, Claus (2017): Kommunale Investitionsschwäche: Engpässe bei Planungs- und Baukapazitäten bremsen Städte und Gemeinden aus, in DIW Wochenbericht,

$11 / 2017$, S. $211-219$

Hesse, Mario / Lenk, Thomas (2013): Finanzielle Belastungen der sächsischen Kommunen aus der Grundsicherung für Arbeitssuchende nach dem SGB II, Arbeitspapier Nr. 44 des Instituts für öffentliche Finanzen und Public Management, Leipzig.

Hesse, Mario / Lenk, Thomas / Lück, Oliver (2013): Gemeindefinanzbericht Sachsen 2012/2013, in: Sächsischer Städte- und Gemeindetag (Hrsg.): Sachsenland-Kurier, Heft 6/2013, Dresden.

Höck, Carl-Friedrich (2016): Wo die Bundesmittel nicht verbaut werden, in: DEMO: Vorwärts Kommunal vom 10. Oktober 2016, online abrufbar unter:

https://www.demo-online.de/artikel/bundesmittel-verbaut, zuletzt aufgerufen am 05.12.2017. 
Institut der deutschen Wirtschaft Köln e. V. (2016): Personalmangel in den Bauämtern, 19.10.2016, online abrufbar unter: https://www.iwd.de/artikel/personalmangel-in-den-bauaemtern-306346/, zuletzt aufgerufen am 30.11.2017.

Kilian, Maike / Hesse, Mario / Redlich, Matthias (2016): Kommunaler Investitionsbedarf im Freistaat Sachsen, Befragung 2016, in: Kompetenzzentrum für kommunale Infrastruktur (Hrsg.): KOMKIS Analyse, Leipzig.

Kratzmann, Alexander / Redlich, Matthias / Hesse, Mario (2016): Eine schmale Brücke in die Zukunft? Stellungnahme zum Förderprogramm des Freistaates Sachsen, in: Kompetenzzentrum für kommunale Infrastruktur Sachsen (Hrsg.): KOMKIS Position, Leipzig.

Kreditanstalt für Wiederaufbau (2017): KfW-Kommunalpanel 2017, Frankfurt am Main.

Lenk, Thomas / Hesse, Mario (2015): Gemeindefinanzbericht Sachsen 2014/2015, in: Sächsischer Städte- und Gemeindetag (Hrsg.): Sachsenland-Kurier Heft 08/2015, Dresden.

Lenk, Thomas / Hesse, Mario / Kratzmann, Alexander (2017): Gemeindefinanzbericht Sachsen 2016/2017, in: Sächsischer Städte- und Gemeindetag (Hrsg.): Sachsenland-Kurier 5/2017, Dresden.

Plaza, Sylwia (2016): Förderprogramme in Sachsen - Sachstand, in: Kompetenzzentrum für kommunale Infrastruktur (Hrsg.): KOMKIS Report, Leipzig.

Rossbach, Henrike (2016): 136 Milliarden Euro zu wenig, in : Frankfurter Allgemeine Zeitung, 27.06.2016, Berlin.

Sächsischer Rechnungshof (2016): Jahresbericht 2016: Band II: Kommunalfinanzen, Ergebnisse der überörtlichen Kommunalprüfung, Leipzig.

Scheller, Henrik / Schneider, Stefan (2016): KfW-Kommunalpanel 2016 in: KfW Bankengruppe (Hrsg.): KfW Research, Frankfurt am Main.

Scheller, Henrik / Schneider, Stefan (2017): KfW-Kommunalpanel 2017 in: KfW Bankengruppe (Hrsg.): KfW Research, Frankfurt am Main.

Staatsministerium der Finanzen des Freistaates Sachsen (2015): Einzelplan 15: Allgemeine Finanzverwaltung, in: Staatsministerium der Finanzen (Hrsg.): Doppelhaushalt 2015/2016, Dresden.

Staatsministerium der Finanzen des Freistaates Sachsen (2016): Sächsisches Förderprofil 2017/2018 zum Sächsischen Staatshaushaltsplan, in: Staatsministerium der Finanzen (Hrsg.): Doppelhaushalt 2016/2017, Dresden.

Staatsministerium für Wirtschaft, Arbeit und Verkehr des Freistaates Sachsen (2013): Medieninformation: Weiterbildung stärken - Benachteiligung fördern: Zusätzliche Mittel aus dem Europäischen Sozialfonds für die Region Leipzig, 19.03.2013.

Staatsministerium für Wirtschaft, Arbeit und Verkehr des Freistaates Sachsen (2014): Operationelles Programm des Freistaates Sachsen für den Europäischen Fonds für regionale Entwicklung (EFRE) in der Förderperiode 2014-2020, von der Europäischen Kommission am 17. November 2014 genehmigte Fassung, Dresden.

Zimmermann, Horst (2009): Kommunalfinanzen, Eine Einführung in die finanzwissenschaftliche Analyse der kommunalen Finanzwirtschaft, 2. überarbeitete Auflage, Berlin. 


\section{Gesetze und Verordnungen}

Gesetz über den Finanzausgleich mit den Gemeinden und Landkreise im Freistaat Sachsen (Sächsisches Finanzausgleichsgesetz - SächsFAG) vom 21. Januar 2013, SächsGVBI. 2013 Nr. 2, S. 95.

Gesetz über die Grundsätze des Haushaltsrechts des Bundes und der Länder (Haushaltsgrundsätzegesetz - HGrG) vom 1. Januar 1970, BGBI.I, S.3122.

Gesetz zur Stärkung der Investitionskraft der kreisangehörigen Gemeinden, Landkreise und Kreisfreien Städte im Freistaat Sachsen (Sächsisches Investitionskraftstärkungsgesetz - SächsInvStärkG), vom 16. Dezember 2015, SächsGVBI. 2015 Nr. 15, S. 656-657.

Haushaltsordnung des Freistaates Sachsen (SäHO) vom 10. April 2001, SächsGVBI. 2001 Nr. 5, S. 153.

Verwaltungsvorschriften des Sächsischen Staatsministeriums der Finanzen zur Sächsischen Haushaltsordnung (VwV-SäHO) vom 27. Juni 2005, SächsABI.SDr. 2005 Nr. 6, S. 226. 
Das Kompetenzzentrum für kommunale Infrastruktur Sachsen (KOMKIS) stellt eine kostenfreie Informations- und Beratungsplattform für die kommunale Ebene in Sachsen dar. Im Schnittstellenbereich zwischen Verwaltung, Wissenschaft und Politik agiert das KOMKIS als kompetenter Informationsgeber, neutralen Vermittler und inhaltlicher Ansprechpartner zu Themen der kommunalen Infrastrukturbeschaffung, -erhaltung und -bewirtschaftung.

Weitere Veröffentlichungsformate abrufbar unter www.uni-leipzig.de/komkis:

\section{KOMKIS Dialog}

\section{KOMKIS Position}

\section{KONKIS Praxis}

KOMKIS Report

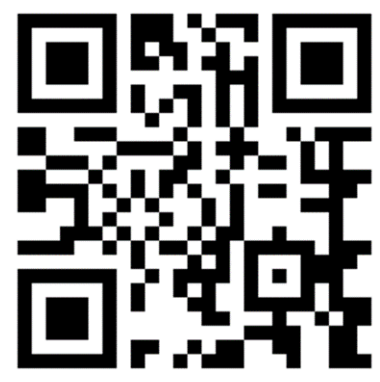

